\title{
A Vibration-Related Design Parameter Optimization Method for High-Speed Elevator Horizontal Vibration Reduction
}

\author{
Lemiao Qiu $\mathbb{D}^{1}{ }^{1}$ Zili Wang $\mathbb{D}^{1},{ }^{1}$ Shuyou Zhang $\mathbb{D},{ }^{1}$ Lichun Zhang, ${ }^{2}$ and Jie Chen ${ }^{1}$ \\ ${ }^{1}$ State Key Laboratory of Fluid Power and Mechatronic Systems, Zhejiang University, Hangzhou, China \\ ${ }^{2}$ Canny Elevator Co., Ltd., Suzhou, China \\ Correspondence should be addressed to Zili Wang; ziliwang@zju.edu.cn
}

Received 13 October 2019; Revised 7 January 2020; Accepted 16 January 2020; Published 13 February 2020

Academic Editor: C. M. Wang

Copyright (c) 2020 Lemiao Qiu et al. This is an open access article distributed under the Creative Commons Attribution License, which permits unrestricted use, distribution, and reproduction in any medium, provided the original work is properly cited.

High-speed elevator horizontal vibration (HsEHV) is a problem that seriously affects ride comfort. To solve this problem, a design parameter optimization method for HsEHV reduction was studied. A dynamic equation of HsEHV was established, and its response value was calculated using a precise integration method. The influence of the design parameters on horizontal vibration was also analyzed. An optimization model of the design parameters for HsEHV reduction was constructed, and the response surface model of objective function (the peak-to-peak value of horizontal vibration acceleration) was constructed using Latin hypercube sampling. We adopted a multiobjective genetic algorithm to optimize the design parameters for horizontal vibration reduction and used the min-max standardization method to select an optimal solution set. Finally, a KLK2 high-speed elevator made by Canny Elevator Co., Ltd., was utilized as an example to analyze the influencing factors of HsEHV, optimize the design parameters to reduce horizontal vibration, and verify the optimized results using numerical calculation and prototype testing.

\section{Introduction}

High-speed elevators are an indispensable vertical transport tool in superhigh-rise buildings. However, elevator vibration exacerbates as the lifting speed increases, which affects ride comfort and ride stability. Determining how to optimize the vibration reduction of elevators has become an important technical difficulty that needs to be urgently solved through research and development of high-performance elevator products. For this reason, many scholars and engineering technicians have conducted research on vibration modeling and analysis of high-speed elevators and vibration suppression methods.

Vibration modeling and analysis of high-speed elevators provide the basis for studying vibration suppression methods and the development of vibration dampers. Fung et al. [1] studied vibration analysis and the vibration suppression control of a moving elevator string with timevarying length and a weight attached at the lower end. Utsunomiya et al. [2] analyzed the vibration of elevators from the guide shoe, which provided a design idea that can effectively reduce the static equilibrium vibration. Arrasate et al. [3] conducted a study of vertical vibrations caused by the torque ripple generated in the elevator drive system and its influence on passenger comfort during elevator travel. Wee et al. [4] investigated nonlinear, velocity-dependent, stick-slip vibrations that occur during sliding metal contact. Guo et al. [5] developed the elevator cabin-slide guide-rail coupled lateral vibration model. This exploration provides the important theoretical foundation for optimal design of a slide guide. Fan and Zhu [6] developed the round elevator traveling cable model using a singularity-free beam formulation. The effects of the vertical motion of the car on the free responses of the traveling cable were investigated. Kobayashi et al. [7] identified the modal parameters of the elevator car using an operational modal analysis and then estimated the stiffness parameters of the elevator car based on these parameters. Yang et al. [8] investigated the couple vibrations of building and elevator ropes using theoretical and experimental verification. The proposed model was then used to predict the sways of practical building and elevator ropes. Wang et al. [9] derived the definite and random part of the acceleration response expressions according to perturbation theory, and the transverse vibration acceleration 
response of the observation point was analyzed. Mei and Chen [10] constructed the system dynamic equations of the high-speed traction elevator, and this vibration behavior was analyzed using the Newmark method. Taplak et al. [11] proposed the adaptive neural network predictor to estimate and evaluate the vibrations on elevator systems. Zhang et al. $[12,13]$ established the nonlinear model of rolling guide shoes. The horizontal vibration responses were analyzed under variation of the parameters and the irregularity of the guide rails. Yani et al. [14] investigated the nonlinear oscillation and stability of the elevator's drum as a singledegree-of-freedom swing system employing the parameter expansion method. Liu et al. [15] established the horizontal vibration dynamic model of the high-speed elevator car by considering the relationships of lateral force and the overturning moment with horizontal displacement, deflection angle displacement, and rated speed.

The research results of vibration suppression are helpful for improving elevator ride comfort and operational stability. Mutoh et al. [16] proposed the active damping control method for superhigh-speed elevators. This method suppresses vibrations by generating the magnetic force needed for suppression only when vibrations of the car frame are produced. Feng et al. [17] designed the robust controller of horizontal vibrations using Lyapunov's method and considering the characteristics of nonlinearity, parameter uncertainties, and external disturbances of the elevator cage. Noguchi et al. $[18,19]$ developed several active suspension systems to reduce the horizontal vibrations of the elevator car. These systems have six actuators that independently activate the guide rollers. Santo et al. [20] investigated the horizontal nonlinear response of a three-degree-of-freedom vertical transportation model excited by guide rail deformations. A control strategy based on the state-dependent Riccati equation was proposed. Kang and Sul [21] proposed a vibration suppression strategy for improving the ride comfort of an elevator using car acceleration feedback compensation. Knezevic et al. [22] proposed the synergistic solution based on the jerk control and upgrade of the speed controller with a band-stop filter to restore lost ride comfort and speed control caused by vibration. Zhang et al. [23] designed the active car shock absorber with a linear motor to effectively suppress high-speed traction elevator vibration. Nakano et al. [24] presented a new control device to suppress horizontal vibration in the elevator cabin. The device consists of two rotary electric motors with eccentric masses that can reduce vibration without producing unwanted vertical vibration. Funai et al. [25] described the control characteristics and experimental results of the two main methods of active vibration control systems. One is the actively controlled roller guide system, and the other is the active control system installed between the car frame and the platform. Otsuki et al. [26] presented the method of vibration control for the elevator rope, which is based on the nonstationary sliding mode control method using an input device with gaps. Arakawa and Miyata [27] developed a new controller with a variable structure that consisted of multiple linear controllers to suppress the vertical vibration of fast elevators. Kim et al. [28] presented an advanced method of selecting the number of poles and slots to reduce the vibration of the traction motor used for the gearless elevator system. Utsunomiya [29] developed the vibration damping device for an elevator. The actuator that generates the vibration damping force acting on an elevator car is provided in parallel with the spring that directs the guide roller against the guide rail. Dai et al. [30] proposed the moving element method which was found to have advantages over the other numerical methods for solving high-speed dynamic response problems. In conjunction with the moving element method, a three-phase computational scheme was proposed to account for the motion of the unsupported sleepers in relation to the truncated rail segment in the moving coordinate system, and the study found that a high-speed train that travels over a discretely supported track produced more severe vibrations than that which travels over a continuously supported track of equivalent foundation stiffness $[31,32]$.

The vibration suppression of the high-speed elevator is often achieved by developing and installing vibration dampers. Typical passive vibration dampers [33-35] include a guide shoe, a shock-absorbing spring, and an elevator car buffer. Typical active vibration dampers [2,16,36,37] include an electromagnetic guide shoe, an electromagnetic damper, and an active hydraulic guide roller. There are many linear or nonlinear elastic elements in a high-speed elevator. However, if the design parameters are not properly selected, highspeed elevators may violently vibrate. The human feeling of vibration is related not only to vibration intensity but also to its frequency and direction. The traditional elevator design process has a large randomness in the selection of the elastic components of the guidance system. It is mainly selected according to the size of the rolling guide shoes, the width of the wheel, and the width of the guide rail. The vibrationrelated design parameter optimization method proposed in this paper theoretically gives the impact of the relevant parameters on the HsEHV system and selects the optimal solution of the relevant parameters to improve the horizontal vibration performance of the high-speed elevator.

The rest of this paper is organized as follows: The HsEHV system is introduced in Section 2. Then, three main influencing factors of HsEHV are analyzed in Section 3. In addition, the vibration-related design parameter optimization problem is modeled in Section 4. To solve this optimization problem, an MOGA-based solution is presented in Section 5. In Section 6, the proposed method is verified with a KLK2 high-speed elevator parameter design process. Finally, the conclusions are drawn in Section 7.

\section{HsEHV System}

2.1. Composition of the HsEHV System. The HsEHV system, as shown in Figure 1, consists of a car system and a guide system. The car system mainly includes a car cab, a car frame, and a car floor frame. The car frame and car cab are connected by the car floor frame. The guide system mainly includes $\mathrm{T}$-section guide rails installed on the hoistway wall of the elevator and the roller guide shoe. Two sets of roller guide shoes are installed on the top of the vertical beam of the car frame, and the other two sets of roller guide shoes are 


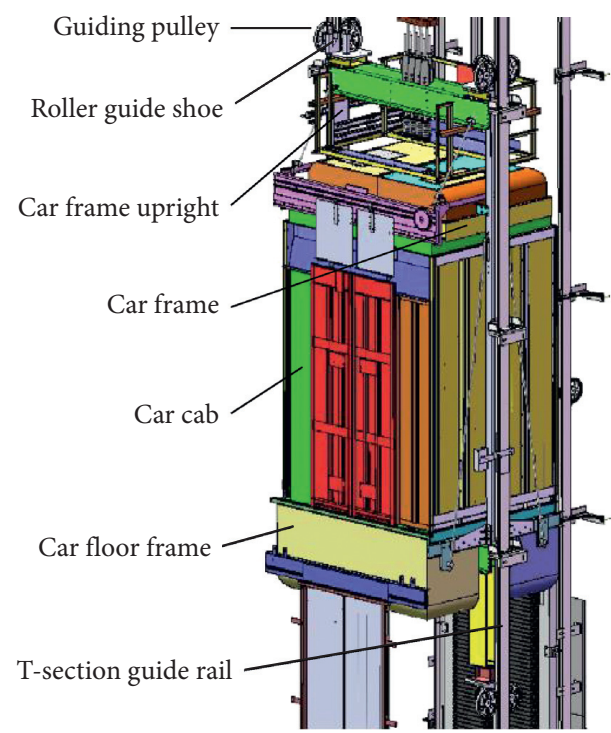

Figure 1: Composition of the HsEHV system.

installed under the safety gear at the bottom of the car frame. Three guiding pulleys of roller guide shoes are attached to the surface of the T-section guide rails by elastic elements.

2.2. Dynamic Model of the HsEHVSystem. In HsEHV, the car translation in the horizontal direction and its rotation around the centroid in the plane are mainly considered. The roller guide shoe can be regarded as a linkage mechanism. The position of the elastic element does not coincide with the center of the guiding pulley. An equivalent elastic element is converted to the center of the guiding pulley. The roller guide shoe is simply a spring and damper in parallel. A dynamic model of the horizontal vibration of a high-speed elevator car is shown in Figure 2.

In Figure 2, $y_{i}(i=1,2,3,4)$ is the displacement of the four guiding pulleys in the horizontal direction, i.e., the unevenness of guide rails at their corresponding positions.

The horizontal vibration system of the high-speed elevator shown in Figure 2 has two degrees of freedom, i.e., $y$ and $\theta$, which can be expressed in the form of the displacement vector:

$$
\{X\}=\{y, \theta\}^{T} .
$$

The horizontal displacement of the four roller guide shoes at their mounting positions on the car frame is as follows:

$$
\left\{\begin{array}{l}
y_{1}^{\prime}=y_{3}^{\prime}=y-l_{1} \theta, \\
y_{2}^{\prime}=y_{4}^{\prime}=y+l_{2} \theta .
\end{array}\right.
$$

The deformation of the four sets of elastic damping elements can be obtained as follows:

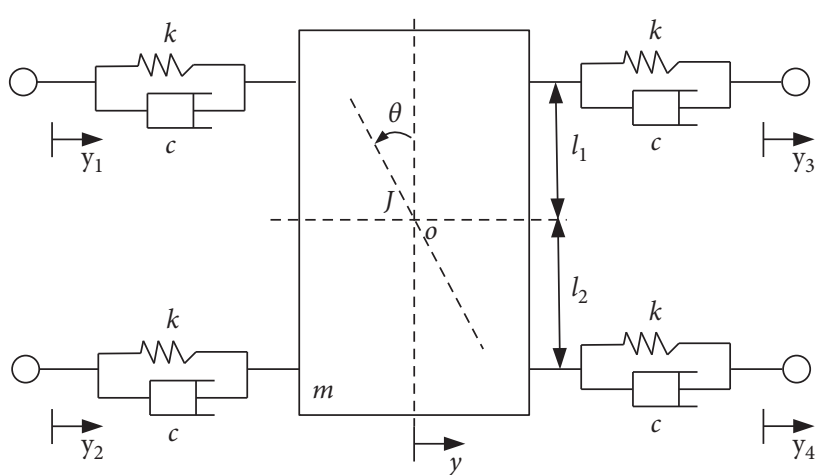

Figure 2: Dynamic model of horizontal vibration of a high-speed elevator car.

$$
\left\{\begin{array}{l}
q_{1}=y_{1}^{\prime}-y_{1}=y-l_{1} \theta-y_{1}, \\
q_{2}=y_{2}^{\prime}-y_{2}=y+l_{2} \theta-y_{2}, \\
q_{3}=y_{3}^{\prime}-y_{3}=y-l_{1} \theta-y_{3}, \\
q_{4}=y_{4}^{\prime}-y_{4}=y+l_{2} \theta-y_{4} .
\end{array}\right.
$$

According to D'Alembert's principle and the dynamic characteristics of elastic elements and damping elements, a dynamic differential equation of the horizontal vibration system of a high-speed elevator was established:

$$
\begin{gathered}
m \ddot{y}=-\left(k q_{1}+c \dot{q}_{1}\right)-\left(k q_{2}+c \dot{q}_{2}\right)-\left(k q_{3}+c \dot{q}_{3}\right)-\left(k q_{4}+c \dot{q}_{4}\right), \\
\begin{aligned}
J \ddot{\theta}= & l_{2} \cdot\left[-\left(k q_{2}+c \dot{q}_{2}\right)-\left(k q_{4}+c \dot{q}_{4}\right)\right] \\
& -l_{1} \cdot\left[-\left(k q_{1}+c \dot{q}_{1}\right)-\left(k q_{3}+c \dot{q}_{3}\right)\right] .
\end{aligned}
\end{gathered}
$$

From equations (4) and (5),

$$
\begin{gathered}
m \ddot{y}+4 c \dot{y}+4 k y+2 c\left(l_{2}-l_{1}\right) \dot{\theta}+2 k\left(l_{2}-l_{1}\right) \theta \\
=\sum_{i=1}^{4}\left(c \dot{y}_{i}-k y_{i}\right), \\
J \ddot{\theta}+2 c\left(l_{1}^{2}+l_{2}^{2}\right) \dot{\theta}+2 k\left(l_{1}^{2}+l_{2}^{2}\right) \theta+2 c\left(l_{2}-l_{1}\right) \dot{y}+2 k\left(l_{2}-l_{1}\right) y \\
=c l_{2}\left(\dot{y}_{2}+\dot{y}_{4}\right)-c l_{1}\left(\dot{y}_{1}+\dot{y}_{3}\right)+k l_{2}\left(y_{2}+y_{4}\right)-k l_{1}\left(y_{1}+y_{3}\right) .
\end{gathered}
$$

The differential equation of the dynamic system could be described in the following general form [38]:

$$
[M]\{\ddot{X}\}+[C]\{\dot{X}\}+[K]\{X\}=\{Q\},
$$

where $[M],[C]$, and $[K]$ are the mass matrix, damping matrix, and stiffness matrix of the system, respectively, and $\{Q\}$ is the excitation matrix. Equations (6) and (7) are expressed in the form of equation (8) as 


$$
\begin{gathered}
{\left[\begin{array}{cc}
m & 0 \\
0 & J
\end{array}\right]\left[\begin{array}{l}
\ddot{y} \\
\ddot{\theta}
\end{array}\right]+\left[\begin{array}{cc}
4 c & 2 c\left(l_{2}-l_{1}\right) \\
2 c\left(l_{2}-l_{1}\right) & 2 c\left(l_{1}^{2}+l_{2}^{2}\right)
\end{array}\right]\left[\begin{array}{c}
\dot{y} \\
\dot{\theta}
\end{array}\right]+\left[\begin{array}{cc}
4 k & 2 k\left(l_{2}-l_{1}\right) \\
2 k\left(l_{2}-l_{1}\right) & 2 k\left(l_{1}^{2}+l_{2}^{2}\right)
\end{array}\right]\left[\begin{array}{l}
y \\
\theta
\end{array}\right]} \\
=\left[\begin{array}{c}
\sum_{i=1}^{4}\left(c \dot{y}+k y_{i}\right) \\
c l_{2}\left(\dot{y}_{2}+\dot{y}_{4}\right)-c l_{1}\left(\dot{y}_{1}+\dot{y}_{3}\right)+k l_{2}\left(y_{2}+y_{4}\right)-k l_{1}\left(y_{1}+y_{3}\right)
\end{array}\right] .
\end{gathered}
$$

The mass matrix, damping matrix, and stiffness matrix of the horizontal vibration system of the high-speed elevator can be obtained from equation (9) as

$$
\begin{aligned}
& {[M]=\left[\begin{array}{ll}
m & 0 \\
0 & J
\end{array}\right],} \\
& {[C]=\left[\begin{array}{cc}
4 c & 2 c\left(l_{2}-l_{1}\right) \\
2 c\left(l_{2}-l_{1}\right) & 2 c\left(l_{1}^{2}+l_{2}^{2}\right)
\end{array}\right],} \\
& {[K]=\left[\begin{array}{cc}
4 k & 2 k\left(l_{2}-l_{1}\right) \\
2 k\left(l_{2}-l_{1}\right) & 2 k\left(l_{1}^{2}+l_{2}^{2}\right)
\end{array}\right],} \\
& {[Q]=\left[\begin{array}{cc}
4 \\
\sum_{i=1}^{4}\left(c \dot{y}_{i}+k y_{i}\right) \\
c l_{2}\left(\dot{y}_{2}+\dot{y}_{4}\right)-c l_{1}\left(\dot{y}_{1}+\dot{y}_{3}\right)+k l_{2}\left(y_{2}+y_{4}\right)-k l_{1}\left(y_{1}+y_{3}\right)
\end{array}\right],}
\end{aligned}
$$

where the design parameters $m, J, k, c, l_{1}$, and $l_{2}$ are contained in matrixes $M, C$, and $K$ and $y_{i}$ and $\dot{y}_{i}(i=1,2,3,4)$ related to the external displacement excitation are contained in the matrix $Q$, which should be determined according to the total profile deviation of the guide rail.

\subsection{Excitation Matrix of the High-Speed Elevator Guide Rail} Profile Deviation. The horizontal vibration excitation of the car mainly comes from the defects of the guide system such as a sudden change in the connection of the guide rail and bending deformation of the guide rail. The displacement excitation of the guide rail is manifested as its straightness deviation, while this periodic excitation will cause the horizontal vibration of the elevator car [39]. For the left and right horizontal vibrations of the car, only one-dimensional bending deformation of the guide rail needs to be considered (forward and backward horizontal vibrations would be similar). One-dimensional bending deformation is wavy in the plane, which is in accordance with the features of the sinusoidal signal. Since the excitation is periodic, it has been tested as a sinusoidal excitation. Compared with other forms of excitation, sine wave excitation is more simple in calculation while ensuring the simulation accuracy [40]. As shown in Figure 3, one-dimensional bending deformation of the guide rail is expressed in the sinusoidal form. $A$ is the amplitude, and $\Delta L$ is the half-wavelength, i.e., the distance between brackets.

The total profile deviation of the guide rail was produced during manufacturing and installation. Because the specific profile deviation and its distribution could not be controlled in the design stage, sinusoidal displacement excitation was used as a disturbance signal. If the car moves upward in the vertical direction in Figure 2, the excitation signals at roller guide shoes 1 and 2 and roller guide shoes 3 and 4 are the same, but there is time lag or lead. The lag or lead time is

$$
t_{0}=\frac{\left(l_{1}+l_{2}\right)}{v} \text {. }
$$

If the excitations at guiding pulleys 2 and 4 are $y_{2}=D(t)$ and $y_{4}=D^{\prime}(t)$, respectively, the excitations at guiding pulleys 1 and 3 are $y_{1}=D\left(t+t_{0}\right)$ and $y_{3}=D^{\prime}\left(t+t_{0}\right)$.

The total profile deviation of the guide rail could be characterized by a sine wave with an amplitude of $A$ and a wavelength of $\lambda$. The left and right guide rails are of the same length and include the same number of brackets, so the wave shapes of the left and right guide rails synchronously change but with different wave amplitudes. The time-domain roughness of the left and right guide rails in the horizontal direction can be expressed as follows:

$$
\begin{aligned}
D(t) & =A_{1} \sin \left(\frac{2 \pi v}{\lambda} t\right), \\
D^{\prime}(t) & =A_{2} \sin \left(\frac{2 \pi v}{\lambda} t\right) .
\end{aligned}
$$

Usually, the length of a single guide rail is $5 \mathrm{~m}$, the distance between brackets is $\Delta L=2.0-2.5 \mathrm{~m}$, and the wave amplitude at the horizontal position is $0.5-1.5 \mathrm{~mm}$. For the corresponding time-domain frequency, the frequency of the 


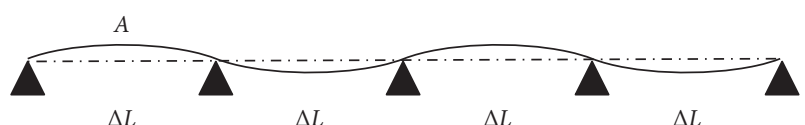

Figure 3: Profile deviation of a high-speed elevator guide rail.

excitation signal is proportional to the speed $v$ of the elevator and inversely proportional to the distance $\Delta L$ between brackets.

The excitation signal wavelength is $\lambda=5 \mathrm{~m}$, while the distance is $\Delta L=2.5 \mathrm{~m}$ between brackets. For the amplitude, the method to accumulate the profile deviation of the guide rail to one side was adopted. While $\omega=2 \pi v / \lambda, y_{i}(i=1,2,3$, 4) in the matrix $Q$ in equation (10) can be expressed as

$$
\begin{aligned}
& y_{1}(t)=A_{1} \sin \left[\omega\left(t+t_{0}\right)\right], \\
& y_{2}(t)=A_{1} \sin (\omega t), \\
& y_{3}(t)=y_{4}(t)=0 .
\end{aligned}
$$

The excitation matrix $Q$ of the profile deviation of the guide rail can be obtained by substituting it in equation (10).

2.4. HsEHV Natural Frequency. The natural frequency of a horizontal vibration system of a high-speed elevator is determined by the mass matrix and stiffness matrix of the system, which is inherent in nature and independent of the external excitation. For a vibration system $[M]\{\ddot{X}\}+[C]$ $\{\dot{X}\}+[K]\{X\}=\{Q\}$, the relationship between the natural frequency $\omega$ and the natural mode of vibration $\{u\}$ is expressed as follows:

$$
\left([K]-\omega^{2}[M]\right)\{u\}=0 .
$$

The characteristic equation of the vibration system is

$$
\Delta\left(\omega^{2}\right)=\left|[K]-\omega^{2}[M]\right|=\left|k_{i j}-\omega^{2} m_{i j}\right|=0 .
$$

The horizontal vibration system of the high-speed elevator is a small damping system. In the modal analysis, the influence of the excitation matrix and damping matrix can be neglected (the natural frequency of the small damping vibration system is approximate to the natural frequency of the undamped system) [41]. By substituting the mass matrix $[M]$ and stiffness matrix $[K]$ in equation (15), we obtain

$$
\left\{\begin{array}{l}
4 k-m \omega_{n 1}^{2}=0, \\
2 k\left(l_{1}^{2}+l_{2}^{2}\right)-J \omega_{n 2}^{2}=0 .
\end{array}\right.
$$

The two natural frequencies of the two-degree-of-freedom horizontal vibration system of the high-speed elevator are solved as

$$
\begin{aligned}
& \omega_{1}=\sqrt{\frac{4 k}{m},} \\
& \omega_{2}=\sqrt{\frac{2 k\left(l_{1}^{2}+l_{2}^{2}\right)}{J}} .
\end{aligned}
$$

\section{Influencing Factors of HsEHV}

The HsEHV system is a typical second-order differential dynamic system. Its input excitation is a time-varying signal. According to equations (9) and (10), the design parameters related to the horizontal vibration response of a high-speed elevator include the mass $m$ of the car system, the moment of inertia $J$, the stiffness $k$ of the roller guide shoe, the damping characteristic $c$, and the positions $l_{1}$ and $l_{2}$ of the guide shoes. The running speed $v$ also affects the horizontal vibration response, but it is an inherent design parameter that cannot be changed. We utilized a KLK2 high-speed elevator from Canny Elevator Co., Ltd., with a speed of $7 \mathrm{~m} / \mathrm{s}$ as an example to analyze the influencing factors of horizontal vibration. Its initial design parameters are listed in Table 1.

The guide rail excitation frequency corresponding to the KLK2 high-speed elevator is approximately $2.0 \mathrm{~Hz}$, which is close to the natural frequency of the system. Humans are sensitive to horizontal vibration in this frequency range. Therefore, the influence of the natural frequency of the system must be considered. By substituting the corresponding data in Table 1 into equation (17), two natural frequencies were obtained: $f_{1}=2.57 \mathrm{~Hz}$ and $f_{2}=3.67 \mathrm{~Hz}$.

3.1. Influence of the Lifting Speed on HsEHV. To analyze the influence of the lifting speed of the KLK2 high-speed elevator on the horizontal vibration of the car and using the elevator speed of $v=1 \mathrm{~m} / \mathrm{s}, 3 \mathrm{~m} / \mathrm{s}, 5 \mathrm{~m} / \mathrm{s}$, and $7 \mathrm{~m} / \mathrm{s}$, the corresponding response values of the horizontal vibration of the car were calculated, as shown in Figure 4.

From the vibration response curves in Figure 4, we can see that the KLK2 high-speed elevator lifts faster, the frequency of the horizontal vibration of the car increases, and the peak-to-peak value of the horizontal vibration acceleration of the car increases. When the lifting speed reaches $7 \mathrm{~m} / \mathrm{s}$, the peak-to-peak value of the horizontal vibration acceleration is $0.350 \mathrm{~m} / \mathrm{s}^{2}$ and affects the ride comfort of the elevator.

\subsection{Influence of the Car System on HsEHV}

3.2.1. Influence of the Moment of Inertia of the Car System on Horizontal Vibration. The equivalent moment of inertia $J$ of the car system is a noncontrollable design parameter. While other design parameters remain unchanged, the change of the moment of inertia affects the horizontal vibration acceleration of the car, as shown in Figure 5. Thus, while the moment of inertia $J$ increases by $300 \%$ from $4000 \mathrm{~kg} \cdot \mathrm{m}^{2}$ to $12000 \mathrm{~kg} \cdot \mathrm{m}^{2}$, the corresponding peak-to-peak value of the horizontal vibration acceleration increases by only $9.5 \%$ from $0.343 \mathrm{~m} / \mathrm{s}^{2}$ to $0.379 \mathrm{~m} / \mathrm{s}^{2}$. The change of the moment of inertia $J$ has a slight influence on the horizontal vibration acceleration of the car.

3.2.2. Influence of the Mass and Load of the Car System on Horizontal Vibration. Since the moment of inertia has a little effect on horizontal vibration, the car system moment of inertia is considered to be the same as other parameters 
TABLE 1: Initial design parameters of the KLK2 high-speed elevator.

\begin{tabular}{lccccccc}
\hline Design parameter & $J$ & $m$ & $\Delta m$ & $k$ & $c$ & $l_{1}$ & $l_{2}$ \\
\hline Value & 8090 & 1535 & 1600 & $1 \times 10^{5}$ & 1000 & 2.8 & 3.7 \\
\hline
\end{tabular}

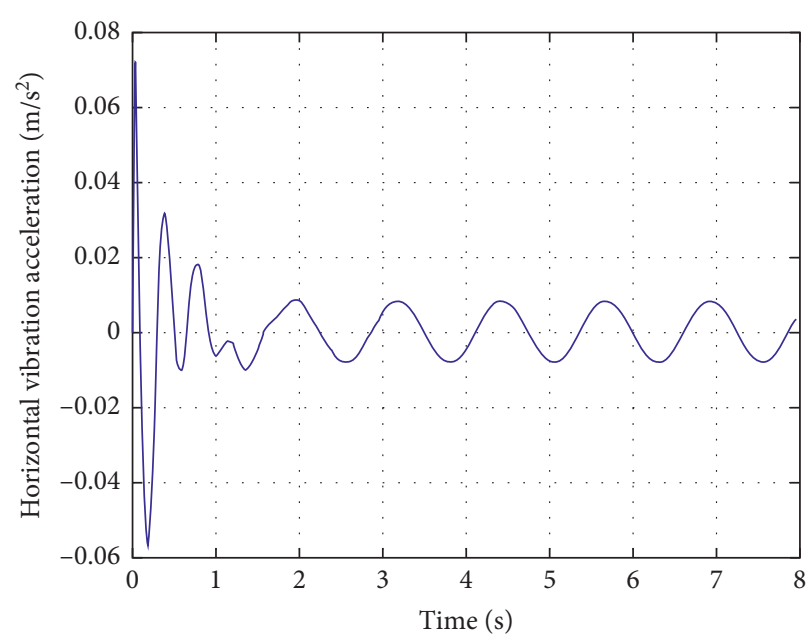

(a)

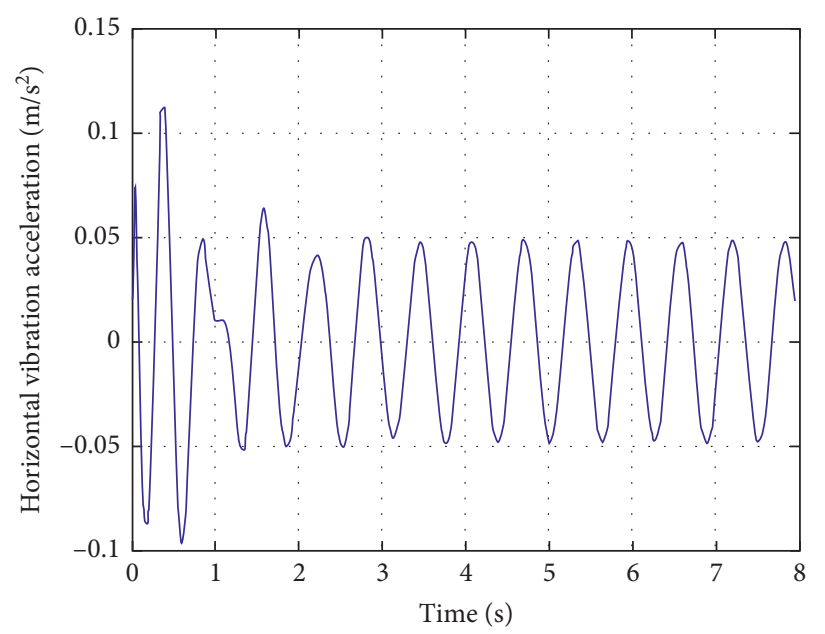

(c)

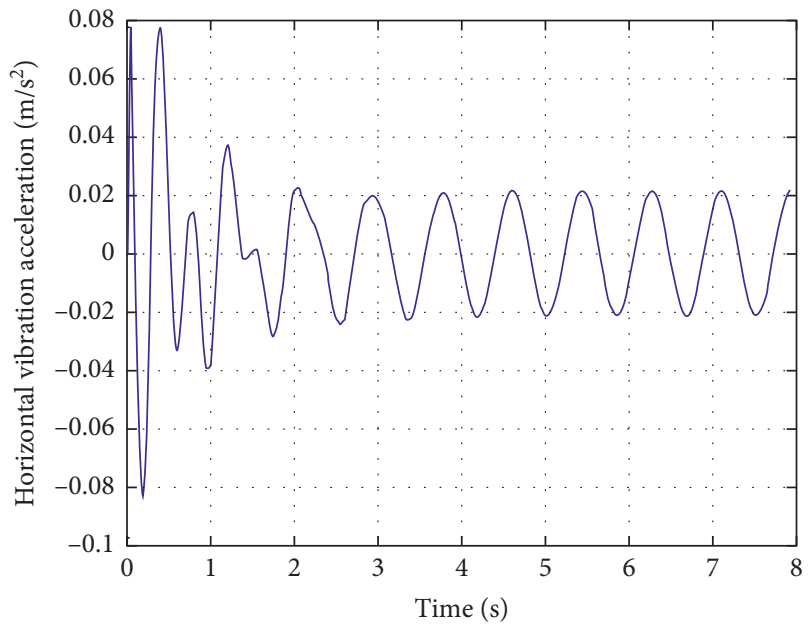

(b)

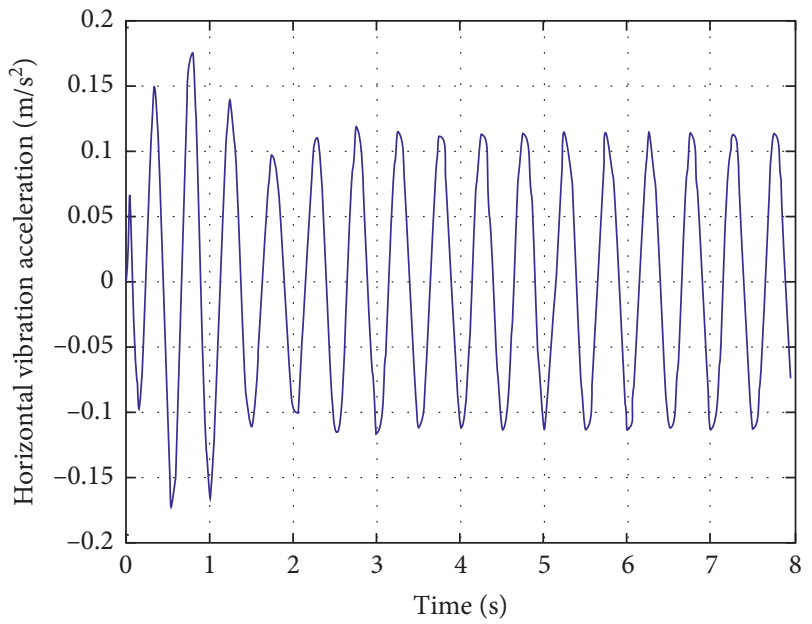

(d)

FIgure 4: Influence of lifting speed on elevator horizontal vibration. (a) $v=1 \mathrm{~m} / \mathrm{s}$. (b) $v=3 \mathrm{~m} / \mathrm{s}$. (c) $v=5 \mathrm{~m} / \mathrm{s}$. (d) $v=7 \mathrm{~m} / \mathrm{s}$.

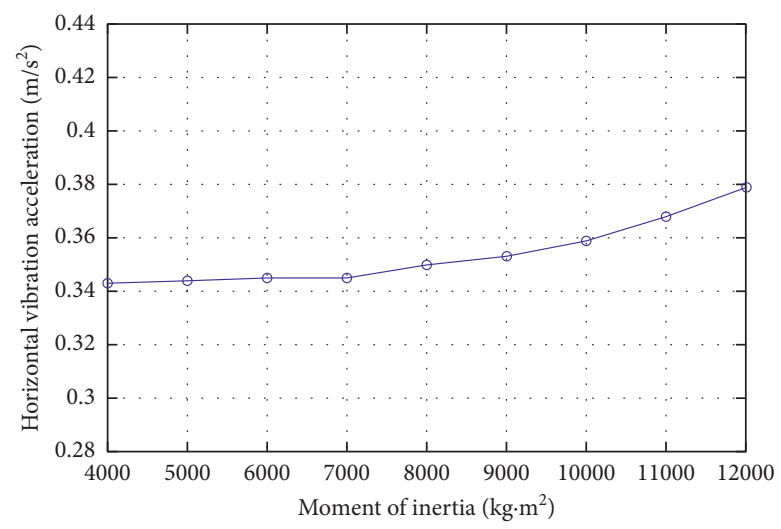

Figure 5: Influence of moment of inertia of the car system on horizontal vibration. 
in elevator load impact analysis. While the KLK2 highspeed elevator lifts at a rated speed of $7 \mathrm{~m} / \mathrm{s}$, the excitation frequency of the guide rail is approximately $2 \mathrm{~Hz}$. The influence of passenger load on horizontal vibration of the $\operatorname{car}\left(k=1 \times 10^{5} \mathrm{~N} / \mathrm{m}\right)$ is shown in Figure 6(a). It illustrates that the passenger load has great influence on horizontal vibration. When the car changes from no load to full load, the horizontal vibration acceleration of the car increases first and then decreases. When the car is fully loaded, the vibration acceleration is equivalent to that when the car is not loaded. According to equation (17), the first-order natural frequency of the system is $f_{1}=2.57 \mathrm{~Hz}$. Therefore, the resonance will not occur under no load and the car horizontal vibration is relatively small. The resonance will occur when the load $\Delta \mathrm{m}$ approximately equals $1001 \mathrm{~kg}$. To avoid the interference of the resonance on the analysis of influencing factors, the equivalent stiffness of the guide shoe was assumed to be $k=300 \mathrm{~N} / \mathrm{m}$. The variation of the peak-to-peak value of the horizontal vibration acceleration under different loads was analyzed, as shown in Figure 6(b). It illustrates that, with an increase of the passenger load, the peak-to-peak value of the horizontal vibration acceleration of the car declines. The passenger load is a noncontrollable design parameter. To avoid resonance under various working conditions, only the natural frequency could be controlled. Therefore, the influence of the passenger load will not be considered in the elevator design, and only the total mass of the car in the no-load situation is used as the design basis.

\subsection{Influence of the Guide System on HsEHV}

3.3.1. Influence of the Roller Guide Shoe Dynamic Parameters on Horizontal Vibration. The main dynamic parameters of the roller guide shoe include its equivalent stiffness $k$ and equivalent damping $c$. To analyze the influence of the roller guide shoe on the horizontal vibration of the car, the other design parameters were kept unchanged, and the response values of the horizontal vibration were calculated with different $k$ values, as shown in Figure 7(a); other design parameters (including the stiffness of the guide shoe) were kept unchanged, and the response values of horizontal vibration were obtained with different $c$ values, as shown in Figure 7(b).

Figure 7 shows that, under the same initial conditions, the greater the equivalent stiffness of the roller guide shoe the larger the peak-to-peak value of the horizontal vibration acceleration of the car and the larger the equivalent damping of the roller guide shoe, the smaller the peak-topeak value of the horizontal vibration acceleration of the car. Therefore, the roller guide shoe with a smaller equivalent stiffness and a larger equivalent damping is beneficial for reducing HsEHV.

3.3.2. Influence of the Guide Shoe Position on Horizontal Vibration. From equation (10) and regarding the matrix expressions of the horizontal vibration system, it can be observed that the position parameters $l_{1}$ and $l_{2}$ of the upper and lower guide shoes have an influence on the stiffness matrix $K$, damping matrix $C$, and excitation matrix $Q$ of the horizontal vibration system. $L=l_{1}+l_{2}$, where is the distance between the upper and lower roller guide shoes which can be measured. Keeping the other design parameters unchanged, the distance $L$ between the roller guide shoes was taken as $6.3 \mathrm{~m}-6.7 \mathrm{~m}$ for the numerical analysis. The results are shown in Figure 8.

Figure 8 shows that the position of the roller guide shoe has a great influence on the horizontal vibration acceleration of a high-speed elevator. With the increase of the distance $L$ between the upper and lower roller guide shoes, the peak-topeak value of the horizontal vibration acceleration of the car shows a downward trend.

\section{Design Parameter Optimization Modeling}

4.1. Optimization Variables and Objectives. Section 2 of this paper shows that the car system has little influence on the horizontal vibration of a high-speed elevator and its guide system has a great influence on HsEHV. The equivalent stiffness of the guide shoe, the equivalent damping of the guide shoe, and the distance between the roller guide shoes are design parameters that have a great influence. Taking $k, c$, and $L$ as the design parameters that need to be optimized for vibration reduction and mass $m$ and moment of inertia $J$ as deterministic design parameters, the design space of the optimized horizontal vibration reduction for the high-speed elevator is expressed as follows:

$$
X=\left[x_{1}, x_{2}, x_{3}\right]=[k, c, L] .
$$

According to equation (17), the first two natural frequencies of the HsEHV can be calculated. The excitation source of elevator car horizontal vibration is usually low frequency. Therefore, the selection of relevant parameters should make the system's natural frequency far away from the human body's most-sensitive horizontal-vibration lowfrequency band of $1-2 \mathrm{~Hz}$ [2]. To prevent resonance, the natural frequency of the system should be far away from the frequency band of $1-2 \mathrm{~Hz}$. The vibration acceleration is a main index affecting the ride comfort. The peak-to-peak value of the horizontal vibration acceleration of the car is used as an evaluation index of vibration performance of the high-speed elevator. According to the international standard for elevator comfort, the horizontal vibration acceleration of the car is less than $25 \mathrm{~cm} / \mathrm{s}^{2}$ [42]. Therefore, for the highspeed elevator, the optimization objective of the horizontal vibration reduction should be as follows:

(1) Peak-to-peak value of the horizontal vibration acceleration is minimized

(2) Natural frequency of the system is maximized, or its opposite number is minimized

The optimization objective function of the design parameters for HsEHV reduction can be described as

$$
\min \left\{d_{1}, d_{2}, d_{3}\right\}
$$




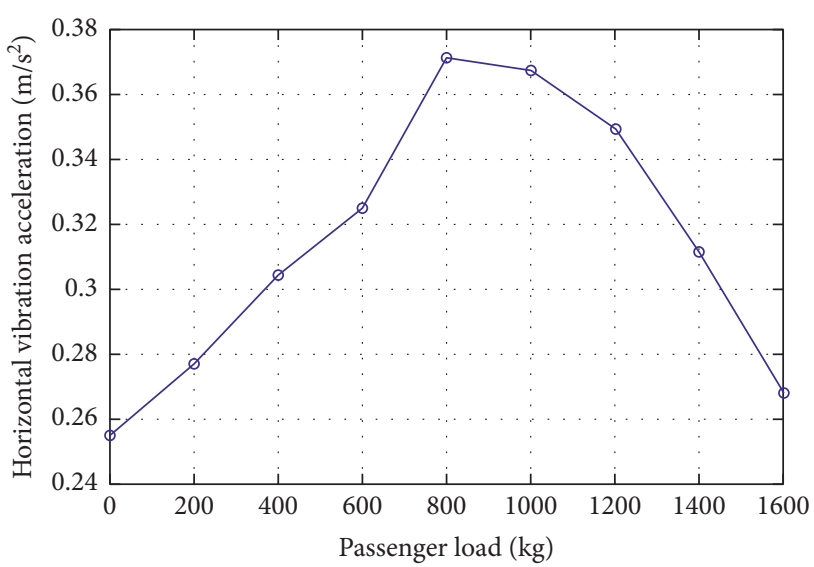

(a)

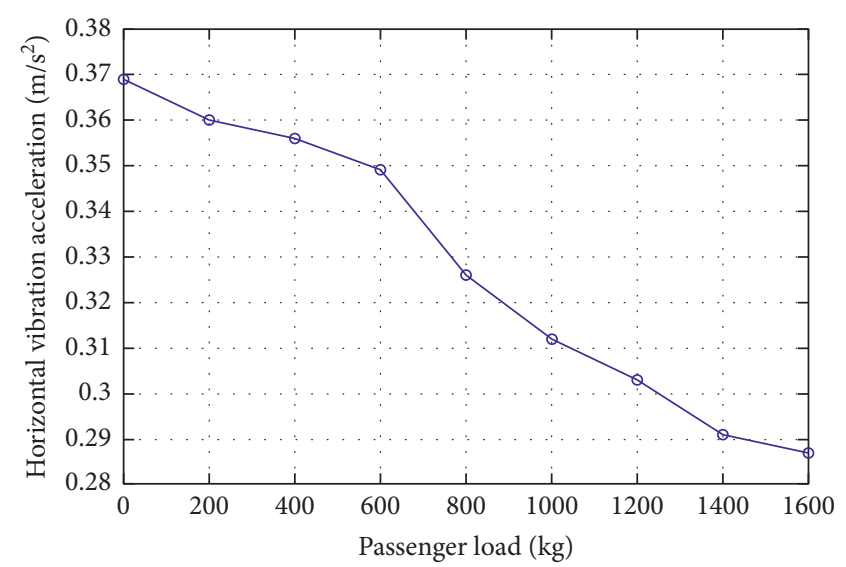

(b)

Figure 6: Influence of passenger load on horizontal vibration of the car. (a) $k=1 \times 0^{5} \mathrm{~N} / \mathrm{m}$. (b) $k=300 \mathrm{~N} / \mathrm{m}$.

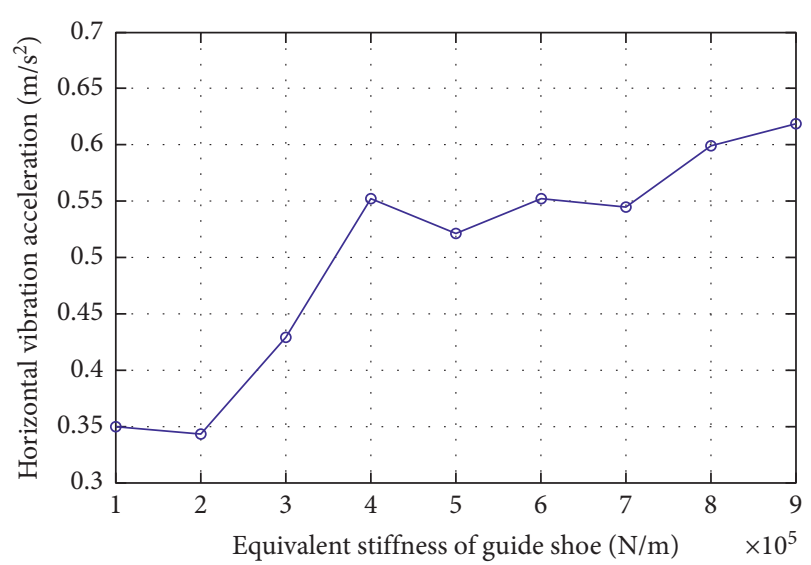

(a)

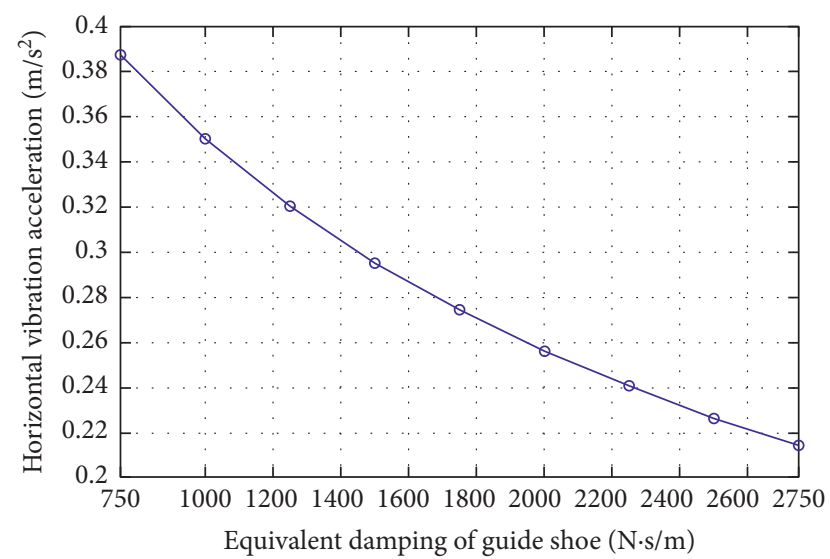

(b)

Figure 7: Influence of dynamic parameters of the roller guide shoe on horizontal vibration. (a) Influence of equivalent stiffness. (b) Influence of equivalent damping.

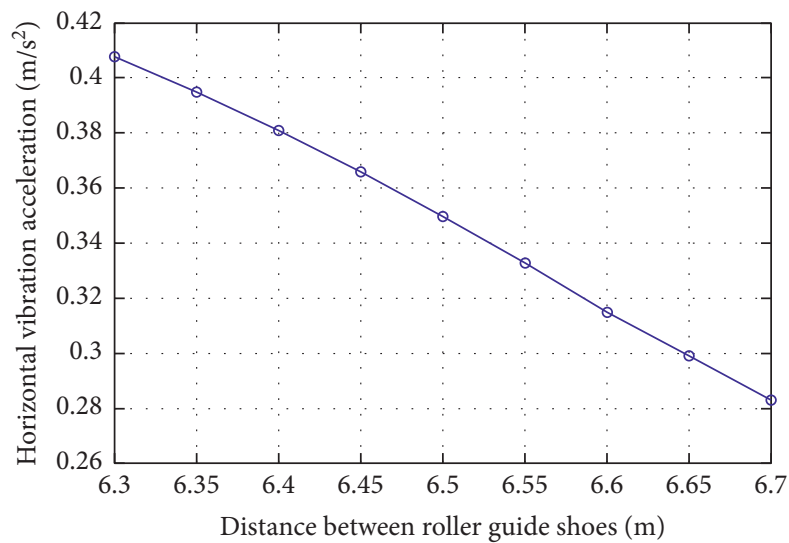

FIGURE 8: Influence of the guide shoe position on horizontal vibration of the car. 
where

$$
\begin{aligned}
& d_{1}=f(X), \quad X=\left[x_{1}, x_{2}, x_{3}\right], \\
& d_{2}=-\frac{1}{2 \pi} \sqrt{\frac{4 x_{1}}{m}}, \\
& d_{3}=-\frac{1}{2 \pi} \sqrt{\frac{2 x_{1}\left[l_{2}^{2}+\left(x_{3}-l_{2}\right)^{2}\right]}{J}} .
\end{aligned}
$$

4.2. Optimization Boundary Restrictions. As shown in Figure 1, the roller guide shoes on the upper part of the car are installed through the car cross-head, which is installed through the upright of the car frame. If the cross-head moves down, the distance $L$ between the guide shoes decreases. This is limited by the installation position on the inspection platform of the car roof; $L$ has a lower limit of $L_{\min }$. If the cross-head moves up, the distance $L$ between the guide shoes increases, and the material cost increases for a longer car frame upright so that $L$ has an upper limit of $L_{\max }$. The constraints of the distance $L$ between the guide shoes can be expressed as $L_{\min } \leq L \leq L_{\max }$. The equivalent stiffness $k$ and equivalent damping $c$ of the guide shoe also set the upper and lower limits according to the design requirements: $k_{\min } \leq k \leq k_{\max }$ and $c_{\min } \leq c \leq c_{\max }$.

The natural frequency must be far away from the frequency band of $1-2 \mathrm{~Hz}$, so its constraints are set as follows (where $\Delta m$ is the full load of the elevator):

$$
\begin{array}{r}
\frac{1}{2 \pi} \sqrt{\frac{4 x_{1}}{m+\Delta m}}>2, \\
\frac{1}{2 \pi} \sqrt{\frac{2 x_{1}\left[l_{2}^{2}+\left(x_{3}-l_{2}\right)^{2}\right]}{J}}>2 .
\end{array}
$$

In summary, the optimization model of the design parameters for HsEHV reduction should be

$$
\begin{array}{ll}
\min & \left\{d_{1}, d_{2}, d_{3}\right\}, \\
\text { s.t. } & x_{i \min } \leq x_{i} \leq x_{i \max }, \quad i=1,2,3, x_{i} \in X, \\
& \frac{1}{2 \pi} \sqrt{\frac{4 x_{1}}{m+\Delta m}}>2 \\
& \frac{1}{2 \pi} \sqrt{\frac{2 x_{1}\left[l_{2}^{2}+\left(x_{3}-l_{2}\right)^{2}\right]}{J}}>2 .
\end{array}
$$

For the KLK2 high-speed elevator, the design parameters were substituted to obtain the optimization model of horizontal vibration reduction, as shown in equation (23). The expression of the objective function $f(x)$ is unknown, and the expressions of $g(x)$ and $h(x)$ are known.

$$
\begin{array}{ll}
\min & \left\{d_{1}, d_{2}, d_{3}\right\}, \\
\text { s.t. } & x_{1} \in[200,500], \\
& x_{2} \in[500,5000], \\
& x_{3} \in[6.4,6.7] \\
& \frac{1}{2 \pi} \sqrt{\frac{4 x_{1}}{m+\Delta m}}>2, \\
& \frac{1}{2 \pi} \sqrt{\frac{2 x_{1}\left[l_{2}^{2}+\left(x_{3}-l_{2}\right)^{2}\right]}{J}}>2,
\end{array}
$$

where $\quad d_{1}=f\left(x_{1}, x_{2}, x_{3}\right), d_{2}=g\left(x_{1}, x_{2}, x_{3}\right)$, and $d_{3}=h$ $\left(x_{1}, x_{2}, x_{3}\right)$.

4.3. Response Surface Model. There are three objective functions in the optimization model of the design parameters for HsEHV reduction, where $d_{2}$ and $d_{3}$ have definite function expressions. However, for each set of definite design parameters $X$, it is difficult to obtain the definite function expression of $d_{1}$. A surrogate model of the objective function $d_{1}$ can be determined by fitting a set of sample points and corresponding output response values.

4.3.1. Latin Hypercube Sampling for Design Parameters. The common sampling methods are importance sampling (IS), adaptive sampling (AS), direction sampling (DS), and Latin hypercube sampling (LHS). IS is one of the classic sampling methods for increasing the efficiency of the Monte Carlo algorithms, which is mainly used to solve the variance reduction problems [43]. AS is proposed to adapt the IS density to the specific problem, which is, after all, a local density-increased sampling method [44]. DS is developed as a dynamically chosen direction sampling method, which is limited to continuous distributions [45]. In the vibrationrelated design parameter optimization case, the values of the design parameters need to be distributed as randomly as possible in the respective sample space. LHS can effectively fill the design space to obtain higher accuracy with fewer samples. This sampling is widely used in large design space sampling. So it is chosen for sampling the vibration-related design parameters. If the dimension of a design space is $N$ and sample number is $M$ for the horizontal vibration reduction optimization of a KLK2 high-speed elevator, then $N=3$ and $M=30$. That is, 30 random samples were generated for the sampling space $X=\left[x_{1}, x_{2}, x_{3}\right]$. For random samples from the LHS method, the response values of the horizontal vibration acceleration were calculated by precise integration [46,47], as listed in Table 2. 
TABLE 2: LHS and its response values of the design parameters of the KLK2 high-speed elevator.

\begin{tabular}{lcccccc}
\hline No. & $x_{1}$ & $x_{2}$ & $x_{3}$ & $d_{1}$ & $d_{2}$ & $d_{3}$ \\
\hline 1 & 360.9 & 1494 & 6.432 & 0.503 & -4.88 & -6.91 \\
2 & 346.6 & 4952 & 6.570 & 0.268 & -4.78 & -6.90 \\
3 & 487.4 & 3031 & 6.457 & 0.404 & -5.67 & -8.06 \\
4 & 321.2 & 3527 & 6.503 & 0.318 & -4.60 & -6.58 \\
5 & 454.3 & 3710 & 6.649 & 0.311 & -5.48 & -7.98 \\
6 & 279.4 & 1853 & 6.478 & 0.383 & -4.29 & -6.12 \\
7 & 239.2 & 637 & 6.687 & 0.357 & -3.97 & -5.92 \\
8 & 226.4 & 4346 & 6.596 & 0.219 & -3.87 & -5.59 \\
9 & 434.3 & 1107 & 6.673 & 0.452 & -5.35 & -7.83 \\
10 & 335.9 & 2489 & 6.485 & 0.391 & -4.71 & -6.72 \\
11 & 255.1 & 4205 & 6.665 & 0.223 & -4.10 & -5.99 \\
12 & 445.6 & 4421 & 6.624 & 0.294 & -5.42 & -7.88 \\
13 & 370.7 & 3448 & 6.619 & 0.327 & -4.95 & -7.18 \\
14 & 406.2 & 2255 & 6.653 & 0.388 & -5.18 & -7.55 \\
15 & 391.7 & 2081 & 6.563 & 0.435 & -5.08 & -7.32 \\
16 & 423.0 & 3297 & 6.521 & 0.384 & -5.28 & -7.57 \\
17 & 265.3 & 3845 & 6.441 & 0.295 & -4.18 & -5.93 \\
18 & 244.6 & 765 & 6.559 & 0.403 & -4.02 & -5.79 \\
19 & 307.7 & 1285 & 6.517 & 0.410 & -4.51 & -6.46 \\
20 & 290.0 & 3071 & 6.542 & 0.306 & -4.38 & -6.29 \\
21 & 494.4 & 4799 & 6.411 & 0.335 & -5.71 & -8.07 \\
22 & 386.0 & 2715 & 6.460 & 0.429 & -5.05 & -7.18 \\
23 & 413.5 & 4601 & 6.588 & 0.300 & -5.22 & -7.55 \\
24 & 353.7 & 1076 & 6.499 & 0.505 & -4.83 & -6.90 \\
25 & 286.3 & 3994 & 6.635 & 0.246 & -4.35 & -6.32 \\
26 & 477.3 & 862 & 6.425 & 0.584 & -5.61 & -7.94 \\
27 & 314.2 & 2392 & 6.605 & 0.334 & -4.55 & -6.60 \\
28 & 203.1 & 1662 & 6.533 & 0.296 & -3.66 & -5.26 \\
29 & 465.0 & 1849 & 6.693 & 0.377 & -5.54 & -8.12 \\
30 & 217.9 & 2765 & 6.405 & 0.299 & -3.79 & -5.35 \\
\hline & & & & & &
\end{tabular}

\subsubsection{Response Surface Model Construction Based on LHS}

(1) Improvement of the Response Surface Model Based on the Radial Basis Function. The response surface model is a simple and effective approximate surrogate model. It is constructed by fitting an unknown function with a polynomial function. The general form of the polynomial function is

$$
\begin{aligned}
f(x)= & \eta_{0}+\sum_{i=1}^{n} \eta_{1} x_{i}+\sum_{i=1}^{n} \eta_{1} x_{i}^{2}+\cdots+\sum_{i=1}^{n} \eta_{m} x_{i}^{m} \\
& +\sum_{j<k, 1=1 \sim m}^{n} \eta_{j k} x_{j}^{l} x_{k}^{m-l} .
\end{aligned}
$$

In solving the coefficients of the response surface function, the least-square method is the most commonly used fitting method to obtain undetermined coefficients with the maximum likelihood estimation method. The fitting precision of an approximate model can be improved by using the radial basis function interpolation method to modify the model by interpolating the residual of the response surface model. For a real model $f(x)$, the radial basis function approximation model can be expressed as follows[48]:

$$
\tilde{f}(x)=\sum_{i=1}^{n} \omega_{i} \psi\left(\left\|x-x_{i}\right\|\right)=\omega^{T} \psi,
$$

where $\omega_{i}$ is the weight coefficient of the $i$-th sample point $x_{i}$, $\omega=\left(\omega_{1}, \omega_{2}, \ldots, \omega_{n}\right)^{T}, \psi\left(\left\|x-x_{i}\right\|\right)$ is the basis function, $\psi=\left(\psi\left(\left\|x-x_{1}\right\|\right), \psi\left(\left\|x-x_{2}\right\|\right), \ldots, \psi\left(\left\|x-x_{n}\right\|\right)\right), \quad$ and $\left\|x-x_{i}\right\|$ are a variable of the basis function used to represent the Euclidean norm between the known sample point $x_{i}$ and the unknown test point $x$.

The commonly used basis functions include the Gaussian function, the polynomial function, and the linear function. In this paper, the Gaussian function was chosen as the basis function for the following reasons: (a) it is radial symmetry of the center point; (b) the curve is smooth, and at any point on the curve, there are all derivatives of any order; (c) the function expression is simple and can be used in a multi-input-multioutput system; and (d) it can be easily calculated. The Gaussian function can be expressed as follows:

$$
\psi(r)=\exp \left(-\frac{r^{3}}{2 \sigma^{2}}\right) .
$$

Assuming that there are $N$ sample sets and corresponding values of residual functions $f\left(x_{i}\right)$ and substituting interpolation conditions $\widetilde{f}\left(x_{i}\right)=f\left(x_{i}\right)$ in equation (26), we can obtain

$$
\begin{aligned}
& \sum_{i=1}^{n} \omega_{i} \psi\left(\left\|x_{1}-x_{i}\right\|\right)=f\left(x_{1}\right) \\
& \sum_{i=1}^{n} \omega_{i} \psi\left(\left\|x_{2}-x_{i}\right\|\right)=f\left(x_{2}\right) \\
& \vdots \\
& \sum_{i=1}^{n} \omega_{i} \psi\left(\left\|x_{n}-x_{i}\right\|\right)=f\left(x_{n}\right)
\end{aligned}
$$

In equation (27), there are $n$ unknown variables $\omega_{i}(i=1$, $2, \ldots, n)$ and $n$ equations so that the unknown variables, i.e., undetermined coefficients, can be determined. Then, an approximate model of the residual term can be obtained by substituting them in equation (27).

(2) Steps for Response Surface Modeling of the Optimization Objective Function Based on LHS. Based on LHS, a response surface model of the optimization objective function of horizontal vibration reduction (the peak-to-peak value of horizontal vibration acceleration) of a high-speed elevator should be constructed as follows:

Step 1: LHS is used to optimize HsEHV reduction, and random samples of the design parameters $X=\left[x_{1}, x_{2}\right.$, $x_{3}$ ] are taken.

Step 2: precise integration is used to calculate the response values of HsEHV for random samples $X=\left[x_{1}\right.$, $\left.x_{2}, x_{3}\right]=[k, c, L]$.

Step 3: according to equations (23) and (26), an approximate response surface model of the optimization objective function of horizontal vibration reduction $d_{1}=f(x)$ is built. 
Step 4: the determination coefficient $R^{2}$ (as an inspection standard) is used to test the accuracy of the model. The closer the value of $R^{2}$ to 1 , the higher the accuracy of the model. $R^{2}$ is shown in the following equation, where $n$ is the sample size, $y_{i}$ is the real response value of a sample point, $\widehat{y}_{i}$ is the fitting value of the corresponding sample point for the model, $\bar{y}$ is the average of the sample response values, and $R$ is the correlation coefficient $(0 \leq R \leq 1)$ :

$$
R^{2}=1 \frac{\sum_{i=1}^{n}\left(y_{i}-\widehat{y}_{i}\right)^{2}}{\sum_{i-1}^{n}\left(y_{i}-\bar{y}\right)^{2}}
$$

Step 5: it is judged whether the response surface model of $d_{1}=f(x)$ can satisfy the accuracy requirement according to the determination coefficient $R^{2}$. If the accuracy requirement is met, the model is used as a surrogate model and Step 7 is executed.

Step 6: the RBF interpolation method is used to correct the residual term of the model. Then, test samples are generated to ensure its accuracy, and the control is then returned to Step 4.

Step 7: a model of the RBF response surface is constructed based on LHS.

(3) A Response Surface Model of the Optimization Objective Function of the Horizontal Vibration Reduction of a KLK2 High-Speed Elevator. A total of 30 random sample points in Table 2 were used to construct the response surface model. Another 10 random sample points were generated for the accuracy test. The model of the optimization objective function (the peak-to-peak value of the horizontal vibration acceleration) of the horizontal vibration reduction of a KLK2 high-speed elevator is shown as

$$
\begin{aligned}
\hat{d}_{1}= & f(X)=-2.4532 \times 10^{-16} x_{1}^{2}+6.1802 \times 10^{-9} x_{2}^{2} \\
& +0.1149 x_{3}^{2}-6.7550 \times 10^{-8} x_{1} x_{2}-5.7386 \\
& \times 10^{-4} x_{1} x_{3}+4.3632 \times 10^{-5} x_{2} x_{3}+6.1695 \\
& \times 10^{-3} x_{1}-6.1694 \times 10^{-4} x_{2}-1.7542 x_{3}+6.5734+R(X) .
\end{aligned}
$$

The variables $X=\left[x_{1}, x_{2}, x_{3}\right]^{T}=[k, c, L]^{T}$ and residual term $R(X)$ can be expressed as equation (30) by the Gaussian radial basis function, and by solving equation (27), the weight coefficient $\lambda_{i}$ is obtained.

$$
R(X)=\sum_{j=1}^{n} \lambda_{j} \cdot \exp \left\{-\frac{1}{2}\left[\left(k-k_{j}\right)^{2}+\left(c-c_{j}\right)^{2}+\left(\alpha-\alpha_{j}\right)^{2}\right]\right\} .
$$

The correlation coefficient $R=0.9903$ and determination coefficient $R^{2}=0.9930$ of the model of the optimization objective function of the horizontal vibration reduction of a KLK2 high-speed elevator were obtained by calculating the test samples. The response of the surface model had high accuracy. The model was used as a surrogate of the actual model, and there was no need for modification of the residual term $R(X)$ using the $\mathrm{RBF}$ interpolation. Therefore, the model of the optimization objective function of the horizontal vibration reduction of a KLK2 high-speed elevator can be expressed as follows:

$$
\begin{aligned}
\hat{d}_{1}= & f(X)=-2.4532 \times 10^{-6} x_{1}^{2}+6.1802 \times 10^{-9} x_{2}^{2} \\
& +0.1149 x_{3}^{2}-6.7550 \times 10^{-8} x_{1} x_{2}-5.7386 \times 10^{-4} x_{1} x_{3} \\
& +4.3632 \times 10^{-5} x_{2} x_{3}+6.1695 \times 10^{-3} x_{1}-6.1694 \\
& \times 10^{-4} x_{2}-1.7542 x_{3}+6.5734
\end{aligned}
$$

where $X=\left(x_{1}, x_{2}, x_{3}\right)^{T}=(k, c, L)^{T}$.

In order to more intuitively show the relationship between the objective function and each design variable, for the vibration acceleration target, the combination of different design variables shows the objective function value predicted by the approximate model, as shown in Figure 9. It shows that there is a highly nonlinear relationship between design variables and target response, which means the response surface model can well fit the relationship between three design variables and the objective function. As for the large number of variable problems, the more complex surrogate models can be utilized.

\section{Design Parameter Optimization Method}

5.1. Optimization Process. A multiple-objective genetic algorithm (MOGA) simulates the process of biological evolution. A population could, in one optimization process, produce a large number of noninferior solutions, which can be applied to multiobjective optimization problems to obtain a Pareto optimal solution set. The response surface model of the optimization objective function of HsEHV reduction can be solved using the MOGA to obtain the Pareto optimal solution set of the multiobjective optimization problem. The optimal solution is then selected as a result of the vibration reduction optimization according to the requirements for vibration performance of the highspeed elevator. The process chart to obtain an optimal solution of the design parameters for $\mathrm{HsEHV}$ reduction based on the MOGA is shown in Figure 10.

5.2. Optimization Correlation Analysis. The initial design parameters of the KLK2 high-speed elevator were $m=1535$, $J=8090, l_{1}=2.8$, and $l_{2}=3.7$. There was an approximate linear relationship between optimization objectives $d_{2}$ and $d_{3}$. As shown in Figure 11, the approximate linear relationship between them can be expressed as follows:

$$
d_{3}=p_{1} \cdot d_{2}+p_{2}
$$

where $p_{1}=1.431$ and $p_{2}=-0.0423$, and $R^{2}$ is calculated to be 0.9896 .

According to equation (32) and as long as the objective $d_{2}$ is satisfied, the objective $d_{3}$ can also be satisfied. Therefore, the optimization objective of the horizontal vibration reduction of a KLK2 high-speed elevator equates to $d_{1}$ and $d_{2}$. Therefore, the model of the optimization objective of the 


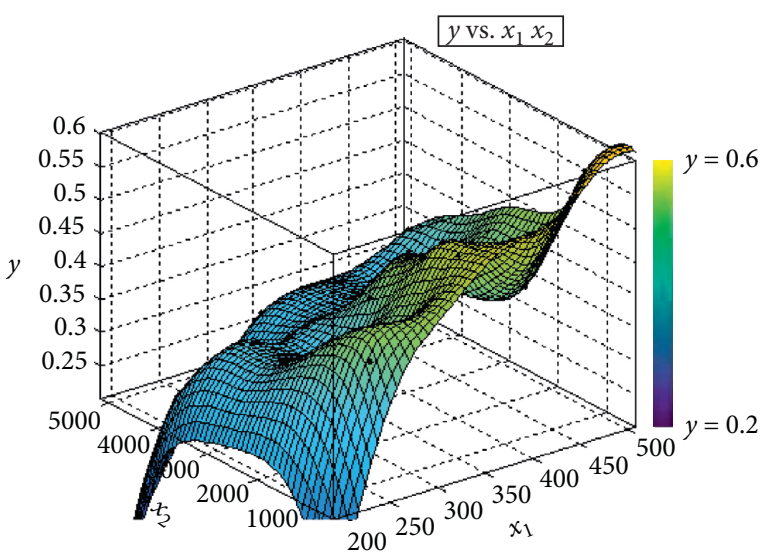

(a)

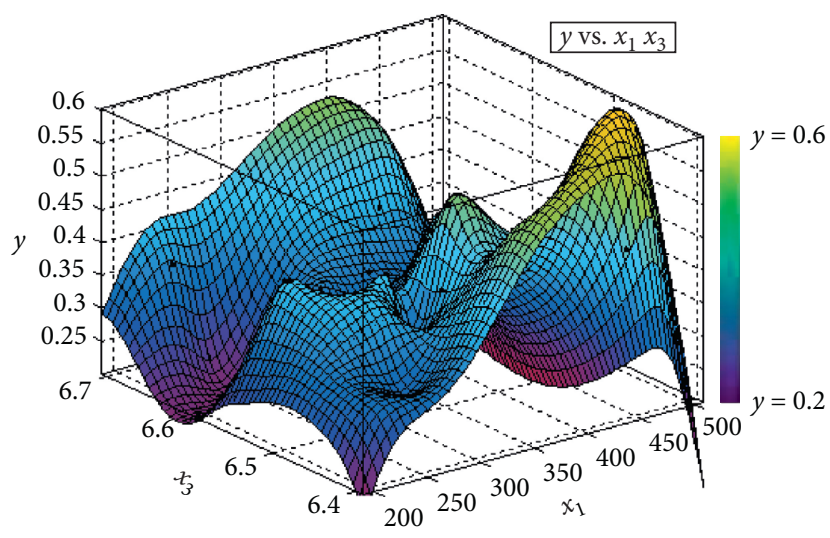

(b)

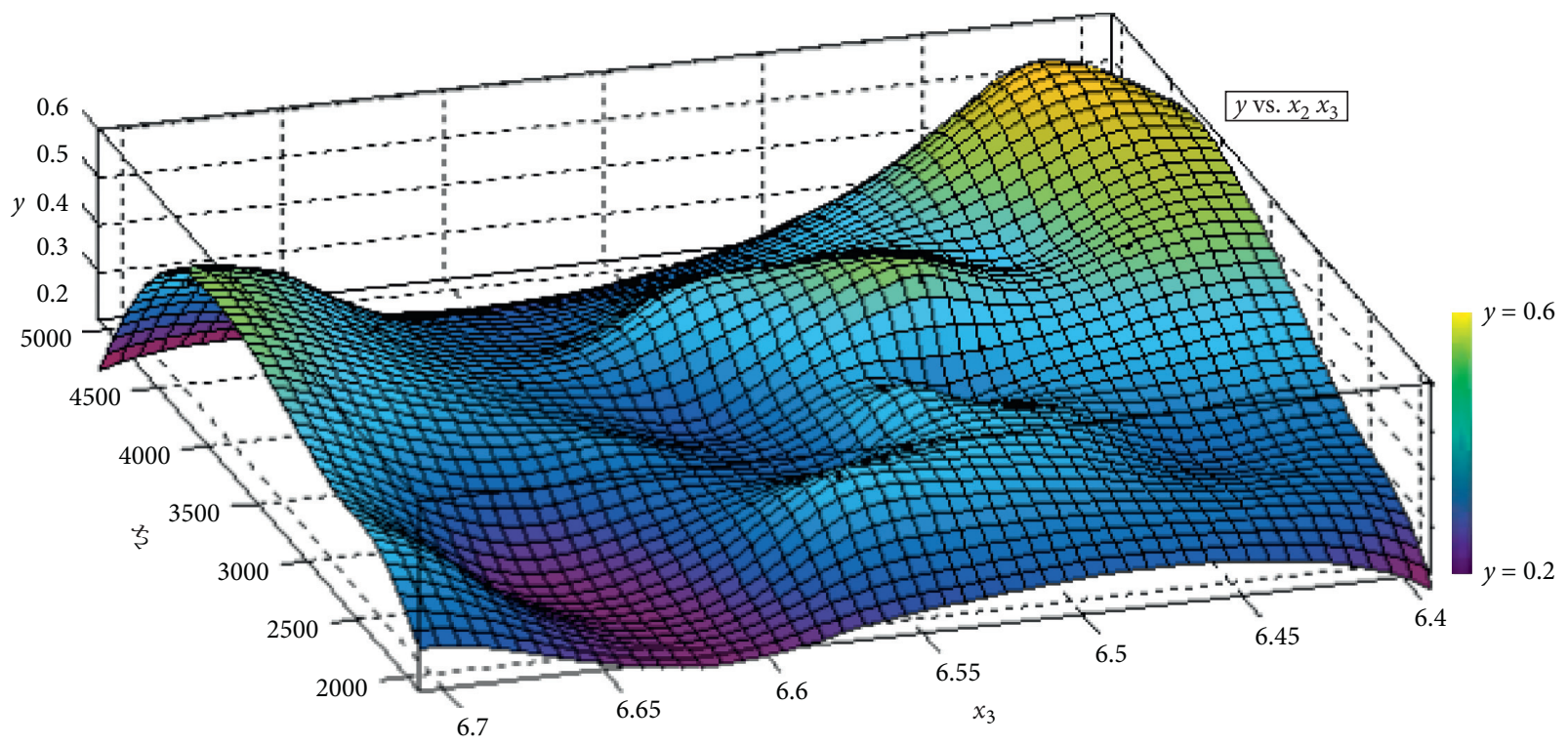

(c)

Figure 9: Response surface of design parameters and HsEHV acceleration peak and peak.

horizontal vibration reduction of a KLK2 high-speed elevator expressed by equation (31) was modified to

$$
\begin{array}{ll}
\min & \left(d_{1}, d_{2}\right), \\
\text { s.t. } & 200 \leq x_{1} \leq 500 \\
& 500 \leq x_{2} \leq 5000 \\
& 6.4 \leq x_{3} \leq 6.7,
\end{array}
$$

where

$$
\begin{aligned}
d_{1}= & -2.4532 \times 10^{-6} x_{1}^{2}+6.1802 \times 10^{-9} x_{2}^{2}+0.1149 x_{3}^{2} \\
& -6.7550 \times 10^{-8} x_{1} x_{2}-5.7386 \times 10^{-4} x_{1} x_{3}+4.3632 \\
& \times 10^{-5} x_{2} x_{3}+6.1695 \times 10^{-3} x_{1}-6.1694 \times 10^{-4} x_{2} \\
& -1.7542 x_{3}+6.5734 \\
d_{2}= & -\frac{1}{2 \pi} \sqrt{\frac{4 x_{1}}{1535}}
\end{aligned}
$$

The MOGA was used to solve the above equation. We selected the initial population as 100 , the iteration as 500 , the crossover probability as 0.8 , and the mutation probability as 0.2 and obtained the Pareto optimal front, as shown in Figure 12. Its horizontal and vertical coordinates represent two optimization objective functions, i.e., the peak-to-peak value of the horizontal vibration acceleration and the opposite number of the first-order natural frequency of the system.

Every point in Figure 12 represents a set of Pareto noninferior solutions. The rightmost noninferior solution has the optimal natural frequency index in all solutions, but its peak-to-peak value of the horizontal vibration acceleration is larger. The peak-to-peak value of the horizontal vibration acceleration of the uppermost noninferior solution is the best in all solutions, but the natural frequency is not satisfactory. Therefore, noninferior solutions need to be selected according to different design requirements. 


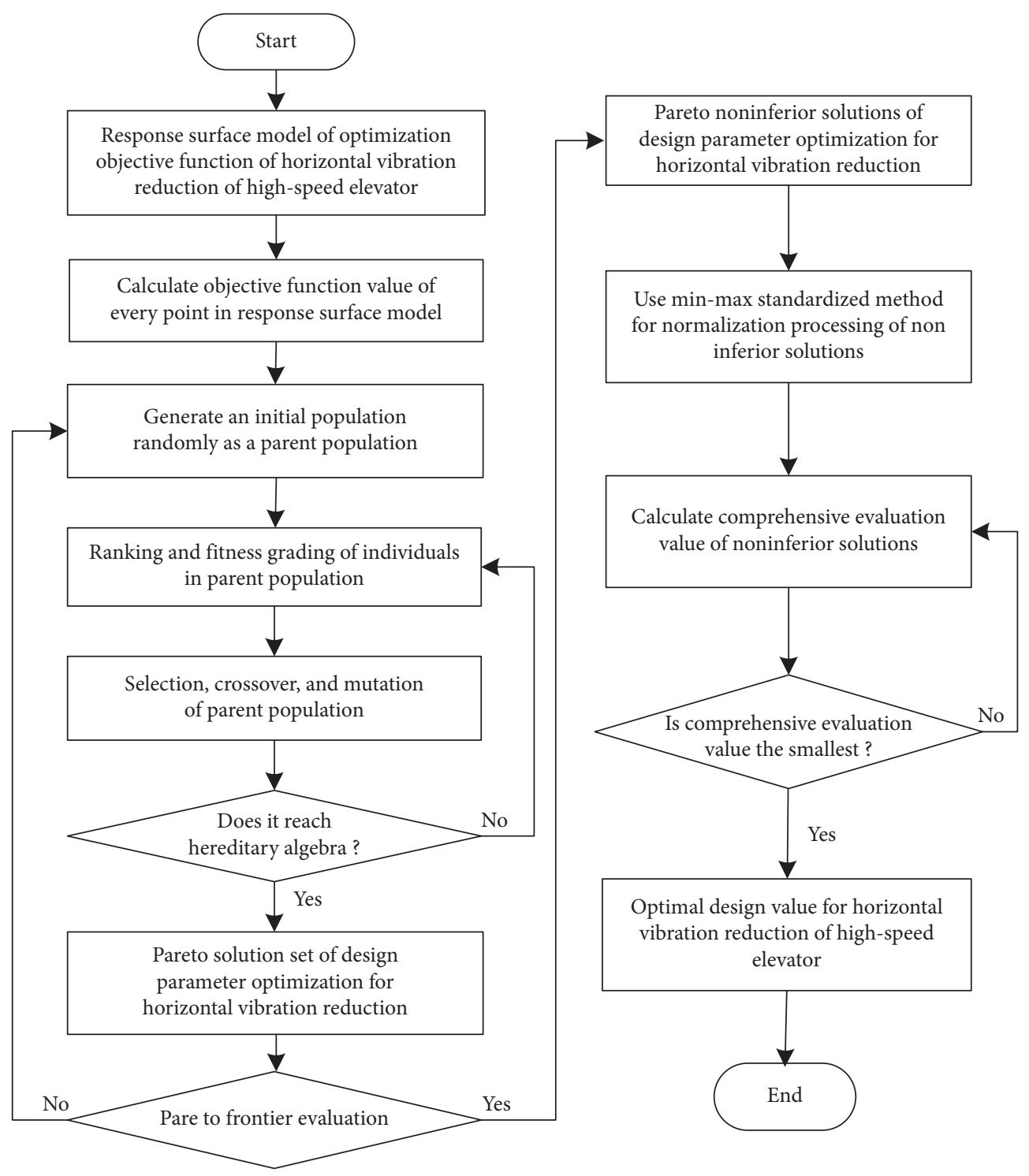

FIGURE 10: Process chart to obtain an optimal solution of the design parameters for HsEHV reduction based on the MOGA.

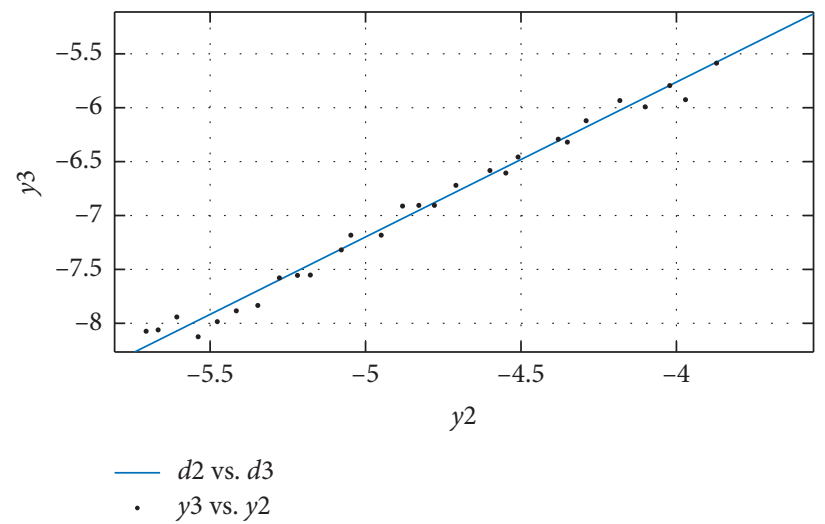

FIGURE 11: Approximate linear relationship between optimization objectives $d_{2}$ and $d_{3}$.

5.3. Optimal Solution Selection. Noninferior solutions corresponding to optimization objectives $d_{1}$ and $d_{2}$ have different dimensions and units, and so the original data need to be standardized for comparison and evaluation. A min-max standardized method was used for normalization processing of the data. In the following equation, $u_{i}$ and $v_{i}$ are the $i$-th 


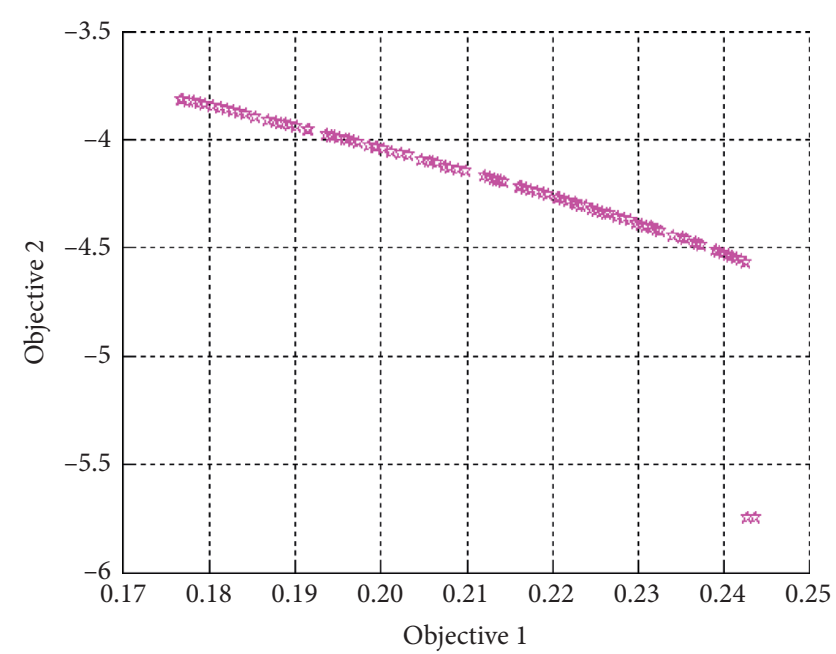

FIgUre 12: Pareto optimal front.

noninferior solution of $d_{1}$ and $d_{2}, u_{\min }$ and $v_{\min }$ are the smallest noninferior solution of $d_{1}$ and $d_{2}, u_{\max }$ and $v_{\max }$ are the largest noninferior solution of $d_{1}$ and $d_{2}$, and $u_{i}^{\prime}$ and $v_{i}^{\prime}$ are the standardized value of the $i$-th noninferior solution of $d_{1}$ and $d_{2}$, respectively, and $0 \leq u_{i}^{\prime} \leq 1$ and $0 \leq v_{i}^{\prime} \leq 1$ :

$$
\begin{gathered}
u_{i}^{\prime}=\frac{u_{i}-u_{\min }}{u_{\max }-u_{\min }}, \\
v_{i}^{\prime}=\frac{v_{i}-v_{\min }}{v_{\max }-v_{\min }} .
\end{gathered}
$$

$u_{i}$ and $v_{i}$ were multiplied by weighted coefficients $\lambda$ and $1-\lambda$, respectively $(0<\lambda<1)$, to obtain the comprehensive evaluation value $\mu_{i}$ :

$$
\mu_{i}=\lambda \cdot u_{i}^{\prime}+(1-\lambda) \cdot v_{i}^{\prime}
$$

The optimization objective $d_{1}$ is the peak-to-peak value of the horizontal vibration acceleration, and the optimization objective $d_{2}$ is the opposite number of the first-order natural frequency of the system. Because the horizontal vibration acceleration has a great influence on the ride comfort, we can use $\lambda=0.6$. After normalization, a comprehensive evaluation value and distribution of the noninferior solutions were obtained, as shown in Figure 13.

According to the principle of minimum optimum selection of the comprehensive evaluation value, $\mu_{31}=0.400$ was selected as an optimal point for the design parameters. The design parameters corresponding to this point and an optimal design value of the vibration reduction are as follows:

$$
\begin{aligned}
& X^{T}=\left(x_{1}, x_{2}, x_{3}\right)=(k, c, L)=(228.84,4754.9,6.7), \\
& Y^{T}=\left(d_{1}, d_{2}\right)=(0.184,-3.89) .
\end{aligned}
$$

The vibration performance evaluation indexes of a KLK2 high-speed elevator before and after horizontal vibration reduction optimization are compared in Table 3 . The peakto-peak value of the horizontal vibration acceleration decreased by approximately $50 \%$ from $0.350 \mathrm{~m} / \mathrm{s}^{2}$ to $0.184 \mathrm{~m} /$ $\mathrm{s}^{2}$. As a result, the ride comfort of the high-speed elevator was greatly improved. The first-order natural frequency of the system was $3.77 \mathrm{~Hz}$ and the second-order natural frequency was $5.70 \mathrm{~Hz}$, which both deviated from the frequency band of $1-2 \mathrm{~Hz}$ that is the most sensitive frequency band of humans to horizontal vibration. Therefore, the possibility of resonance was reduced.

\section{Verification with a KLK2 High- Speed Elevator}

6.1. Numerical Simulation Verification. An optimization objective function of vibration reduction of a KLK2 highspeed elevator was an approximate model, and its optimized results need to be verified using a numerical calculation. For design parameters $X^{T}=\left[x_{1}, x_{2}, x_{3}\right]=[k, c, L]=(228.8,4755$, 6.7), a precise integration method was used to calculate the numerical solution as follows: $Y^{T}=\left(a_{y}, f_{1}, f_{2}\right)=(0.179,3.75$, 5.70). In addition, the numerical solution curve of the horizontal vibration response is shown in Figure 14.

For the influence of the passenger load on the horizontal vibration of the KLK2 high-speed elevator after vibration reduction optimization, the results of the numerical calculation are shown in Table 4.

Figure 14 shows that the numerical solution of the peakto-peak value of horizontal vibration acceleration $\left(0.179 \mathrm{~m} / \mathrm{s}^{2}\right)$ is highly consistent with the response value $\left(0.184 \mathrm{~m} / \mathrm{s}^{2}\right)$ obtained by fitting the approximate model defined by equation (37) (with a difference of only $2.7 \%$ ). Table 4 shows that the passenger load has little influence on the peak-to-peak value of the horizontal vibration acceleration of the high-speed elevator, and the natural frequency of the system still keeps enough margin for the excitation frequency under the full-load condition. Using a numerical calculation, it was verified that both the response surface model and the optimization method of design parameters for the horizontal vibration reduction of a KLK2 high-speed elevator were effective.

According to the results obtained above, the discussion of the effectiveness of the proposed optimization method is presented by comparing with two other typical multiobjective algorithms (NSGA-II [49] and IP-MOEA [50]). To compare the performance of the three algorithms in a fair way, the same parameters are set in all three algorithms: we selected the initial population as 100 , the iteration as 500 , the crossover probability as 0.8 , and the mutation probability as 0.2 . To measure the algorithmic performance, the hypervolume index $(H(N))$, the distribution degree $(D(x))$, and the computing time $(T(x))$ (Limbourg et al. [50]) are calculated. The hypervolume index is calculated as

$$
H(N):=\Lambda\left(\bigcup_{f(x) \in N}\left\{x \mid f\left(x_{\mathrm{ref}}\right)>y>f(x)\right\}\right),
$$

where $N$ is a standard nondominant set, $x_{\text {ref }}$ represents the reference point, $\Lambda(\cdot)$ is the Lebesgue measurement, and $>$ represents the Pareto dominant relationship. The hypervolume index can not only reflect the degree of approximation of the Pareto front and the real Pareto front but also characterize the distribution of the Pareto front. The larger the hypervolume index is, the closer the front of the method 


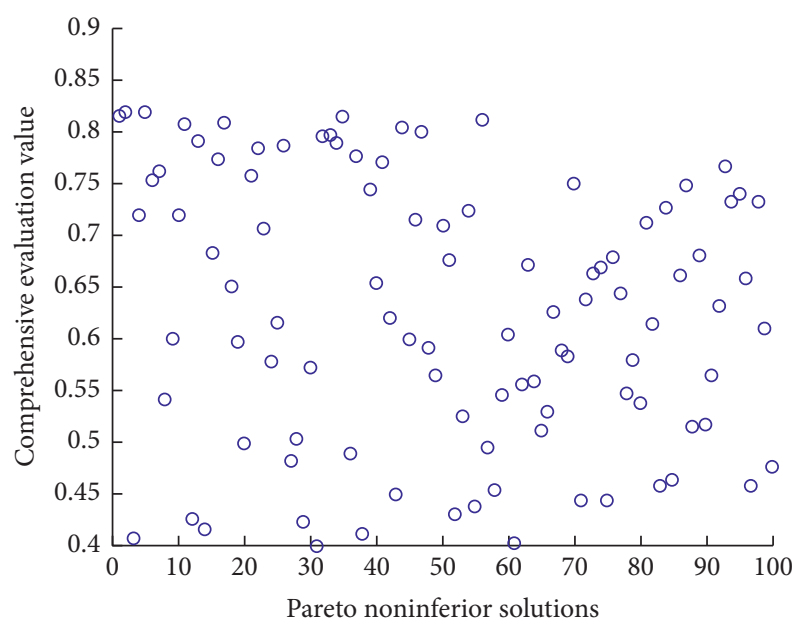

Figure 13: Comprehensive evaluation value and distribution of Pareto noninferior solutions.

TABLE 3: Comparison of the various indexes before and after optimization of horizontal vibration reduction.

\begin{tabular}{lccc}
\hline Items to be compared & $\begin{array}{c}\text { Peak-to-peak value of the horizontal } \\
\text { vibration acceleration }\left(\mathrm{m} / \mathrm{s}^{2}\right)\end{array}$ & $\begin{array}{c}\text { The first-order natural } \\
\text { frequency }(\mathrm{Hz})\end{array}$ & $\begin{array}{c}\text { The second-order natural } \\
\text { frequency }(\mathrm{Hz})\end{array}$ \\
\hline $\begin{array}{l}\text { Before the optimization of } \\
\text { vibration reduction }\end{array}$ & 0.350 & 2.57 & 3.67 \\
\hline $\begin{array}{l}\text { After the optimization of } \\
\text { vibration reduction }\end{array}$ & 0.184 & 3.77 & 5.70 \\
\hline
\end{tabular}

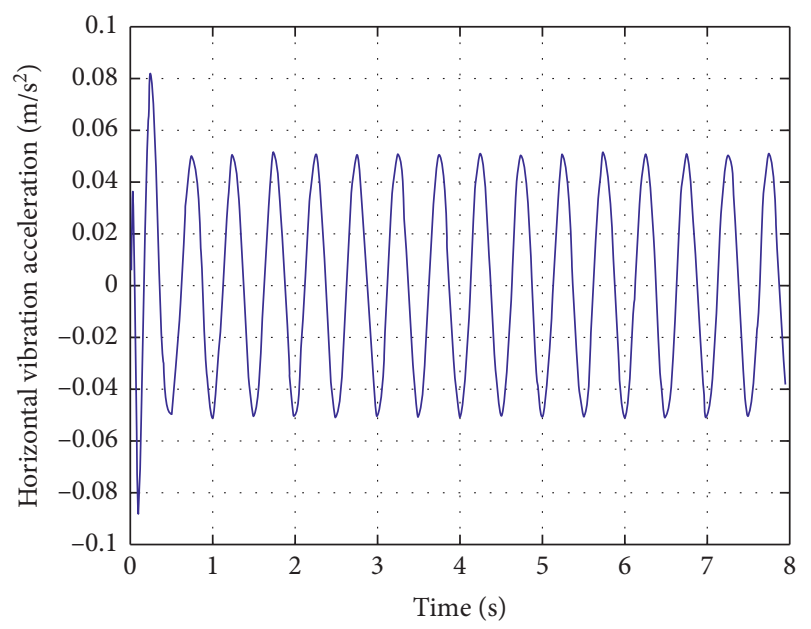

FIgURE 14: Horizontal vibration response curve after vibration reduction optimization.

to the Pareto front is, and also the better the distribution of the front points is. In addition, generational distance (GD) can further quantify the degree of approximation, which can be calculated as

$$
\mathrm{GD}=\sqrt{\sum_{i=1}^{N_{K}} \frac{r_{i}^{2}}{N_{K}}},
$$

where $N_{K}$ denotes the solution numbers in the Pareto front and $r_{i}$ denotes the shortest distance between the $i$-th obtained Pareto solution and the Pareto front. GD reflects the degree to which the Pareto solution obtained by the algorithm approximates the real Pareto solution. The smaller the GD is, the closer the Pareto solution to the real Pareto solution is and the higher the accuracy of the algorithm is. These quantities are recorded when the vibration optimization problem is solved using the three algorithms (NSGAII, IP-MOEA, and MOGA). The hypervolume indexes of three algorithms are shown in Figure 15, in which one $H(N)$ value is taken every 10 generations. The figure illustrates the following: (a) With the increase of evolutionary generations, the performance of the Pareto optimal solution set obtained by the three methods increases. The Pareto front of the 
TABLE 4: Influence of the passenger load on horizontal vibration after vibration reduction optimization.

\begin{tabular}{|c|c|c|c|c|c|}
\hline Passenger load $(\mathrm{kg})$ & 0 & 400 & 800 & 1200 & 1600 \\
\hline Peak-to-peak value of the horizontal vibration acceleration $\left(\mathrm{m} / \mathrm{s}^{2}\right)$ & 0.178 & 0.174 & 0.185 & 0.177 & 0.183 \\
\hline The first-order natural frequency $(\mathrm{Hz})$ & 3.77 & 3.46 & 3.15 & 2.91 & 2.72 \\
\hline The second-order natural frequency $(\mathrm{Hz})$ & 5.70 & 5.70 & 5.70 & 5.70 & 5.70 \\
\hline
\end{tabular}

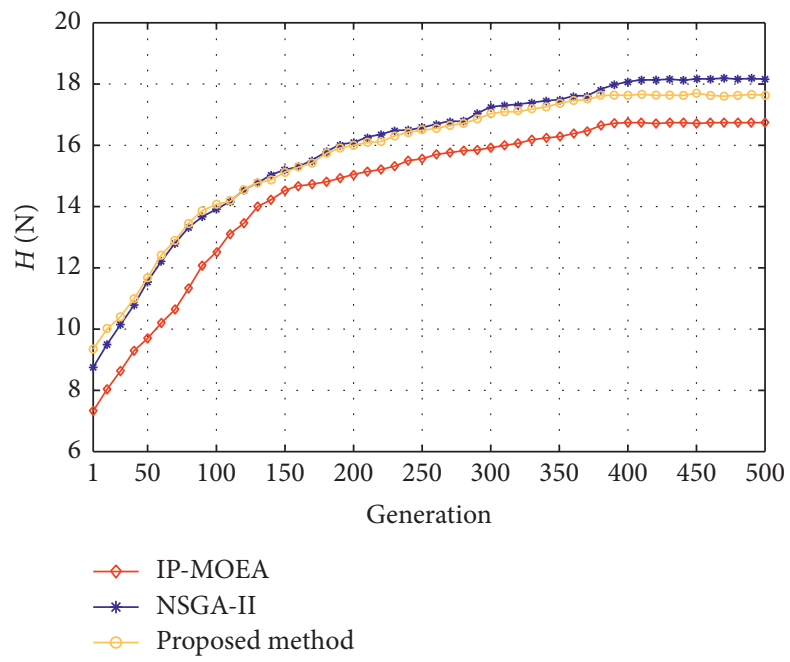

FIGURE 15: Hypervolumes of three algorithms (median).

TABle 5: Average GD and computing time of 10 tests.

\begin{tabular}{lcr}
\hline & GD & Computing time (s) \\
\hline NSGA-II & 1.021 & 5.14 \\
IP-MOEA & 3.244 & 5.77 \\
MOGA & 1.543 & 3.25 \\
\hline
\end{tabular}

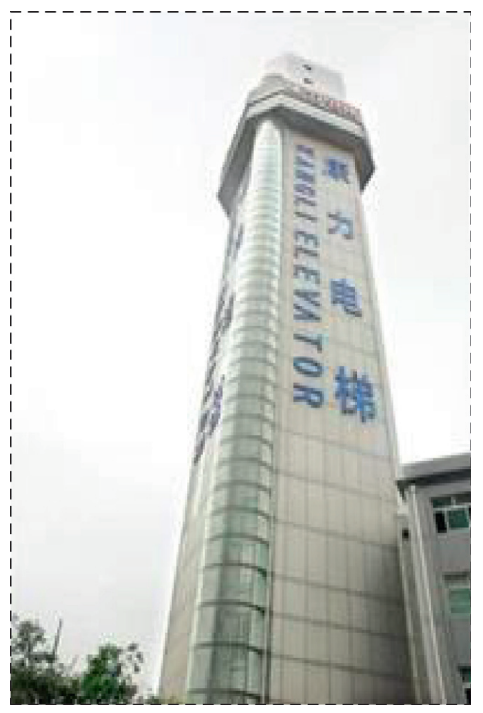

(a)

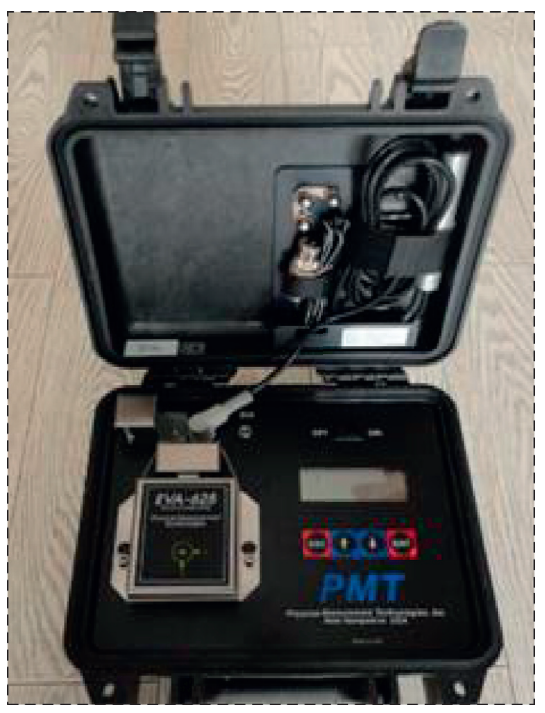

(b)

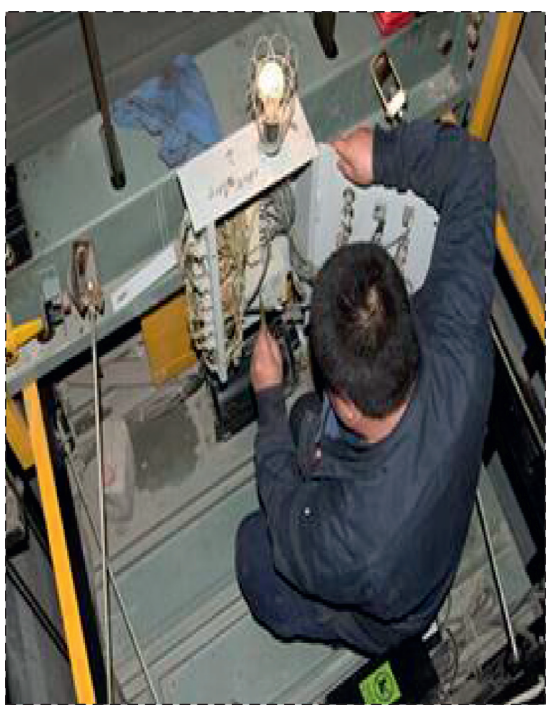

(c)

Figure 16: Horizontal vibration performance test of the KLK2 high-speed elevator prototype. (a) Elevator experimental tower. (b) PMT EVA-625. (c) Test site. 


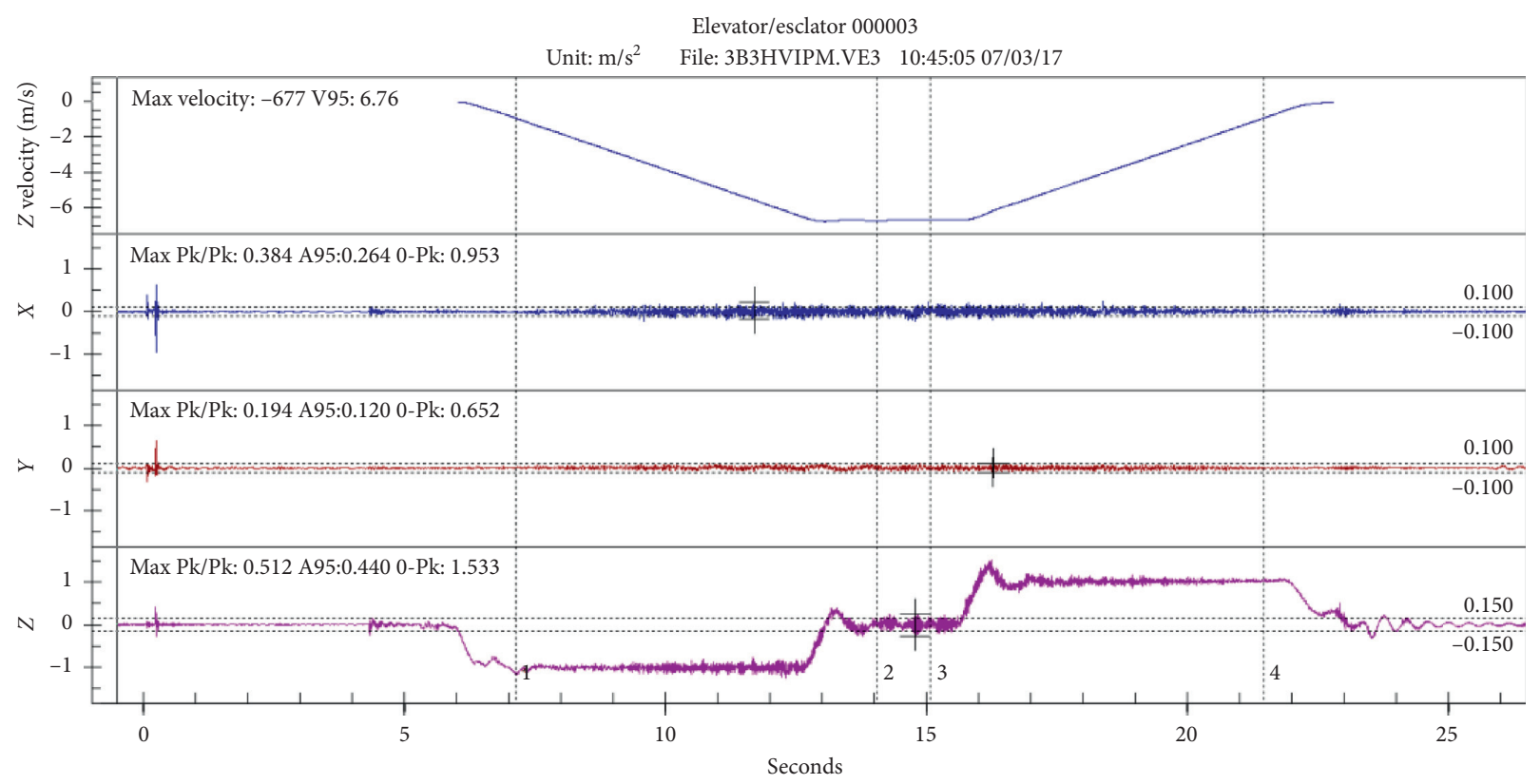

FIGURE 17: Curves of lifting speed and vibration acceleration of the KLK2 high-speed elevator prototype.

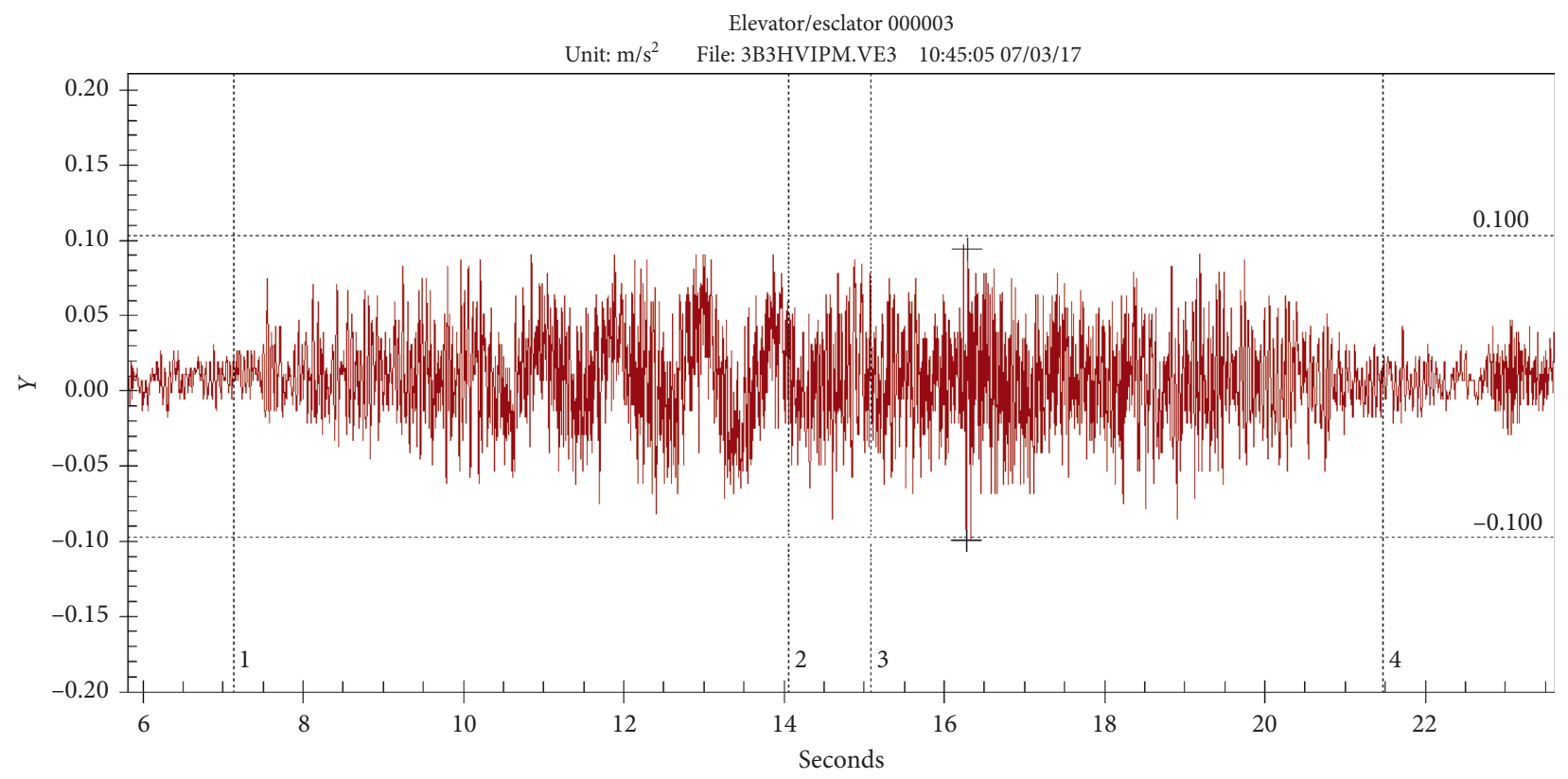

FIGURE 18: Horizontal vibration acceleration curve of the KLK2 high-speed elevator prototype.

solution synchronously gets closer to the real Pareto front. (b) For the same evolution generation, $H(N)$ of the algorithm used in this paper is obviously larger than $H(N)$ of IPMOEA. (c) In contrast, $H(N)$ of the algorithm used in this paper is close to that of NSGA-II in every evolution generation. To reduce the experimental error, the test was performed 10 times. The average GD and the computing time of 10 tests after 500 iterations are shown in Table 5. The algorithms' performance and time consumption are comprehensively taken into account, and the algorithm used in this paper is suitable for solving the HsEHV design parameter optimization problem.

6.2. Experiment Verification. Canny Elevator Co., Ltd., has adopted the method described in this paper in researching and developing its KLK2 high-speed elevator for horizontal vibration reduction optimization. To verify the horizontal vibration damping effect, a prototype of the KLK2 highspeed elevator was tested in an experimental elevator tower 
of the Canny company. Figure 16(a) shows the elevator experimental tower, Figure 16(b) shows an EVA-625 elevator vibration analysis system of PMT (Physical Measurement Technologies, Inc.) [51], and Figure 16(c) shows the actual test site.

EVA-625 was placed on the floor of the car of the prototype. The running data of the KLK2 high-speed elevator prototype measured by EVA-625 included elevator lift speed $(\mathrm{m} / \mathrm{s})$ in the vertical direction and vibration acceleration $\left(\mathrm{m} / \mathrm{s}^{2}\right)$ in the $X, Y$, and $Z$ directions, as shown in Figure 17 .

The vibration acceleration curve in the $Y$ direction (i.e., horizontal direction) in Figure 15 was locally magnified, as shown in Figure 18.

The time-domain curve of the horizontal vibration acceleration of a KLK2 high-speed elevator prototype recorded by EVA-625 is shown in Figures 15 and 16. As the prototype gradually lifts faster, the horizontal vibration showed an increasing trend with its maximum value while the prototype ran at its rated speed of $v=7 \mathrm{~m} / \mathrm{s}$. At that time, the peakto-peak value of the horizontal vibration acceleration of the car was $\max P_{k} / P_{k}=0.194 \mathrm{~m} / \mathrm{s}^{2}$ and $A_{95}=0.122 \mathrm{~m} / \mathrm{s}^{2}$, which was $44.6 \%$ lower than the peak-to-peak value of the horizontal vibration acceleration $\max P_{k} / P_{k}=0.350 \mathrm{~m} / \mathrm{s}^{2}$ before optimization of the vibration reduction in Figure $4(\mathrm{~d})$ of this paper. Both peak-to-peak values of horizontal vibration acceleration and the A95 value of the prototype met relevant standards of ISO/TC178 [42]; the maximum difference was approximately $10 \%$ compared with the peak-to-peak value of the horizontal vibration acceleration obtained by numerical simulation in Table 4 . Considering that the numerical simulation was conducted under simplified and ideal conditions and installation and measurement of the KLK2 high-speed elevator prototype caused certain errors, the results are within an acceptable range. Therefore, the optimization method of the design parameters for HsEHV reduction that is proposed in this paper was verified in prototype testing.

\section{Conclusion}

To improve the running stability and ride comfort of a highspeed elevator, we analyzed the influencing factors of HsEHV and proposed an optimization method of the design parameters for HsEHV reduction. The main technical characteristics of this paper are as follows:

(1) A dynamic equation of HsEHV was obtained. According to the sinusoidal signal characteristic of horizontal vibration excitation, an excitation matrix of the profile deviation of the guide rails was constructed. With a KLK2 high-speed elevator of Canny Elevator Co., Ltd., as an example, the influencing factors of horizontal vibration were analyzed. The results show that the design parameters of the car system have little influence on $\mathrm{HsEHV}$, while the design parameters of the guide system have a great influence on HsEHV.

(2) An optimization model of the design parameters for $\mathrm{HsEHV}$ reduction was built. The response surface model of the optimization objective function of horizontal vibration reduction (the peak-to-peak value of horizontal vibration acceleration) was established using LHS. The optimization model of the design parameters for HsEHV reduction was solved using a genetic algorithm, and its optimal solution set of vibration reduction was selected using a min-max standardization method to realize the optimization of the design parameters for HsEHV reduction.

(3) The design parameters of a KLK2 high-speed elevator were optimized for horizontal vibration reduction, and the results were verified by numerical calculation and prototype testing. The numerical results indicate that the numerical solution of the peak-to-peak value of horizontal vibration acceleration was highly consistent with the response value of the model of optimization objective function of horizontal vibration reduction. The peak-to-peak value of horizontal vibration acceleration $\max P_{k} /$ $P_{k}=0.194 \mathrm{~m} / \mathrm{s}^{2}$ of the prototype was obtained by testing with a maximum difference of approximately $10 \%$ with a peak-to-peak value of horizontal vibration acceleration from numerical simulation, which met relevant technical standards of ISO/TC178. Therefore, the optimization method of the design parameters for HsEHV reduction was verified.

\section{Nomenclature}

c: $\quad$ Equivalent damping of the guide shoe $(\mathrm{N} \cdot \mathrm{s} / \mathrm{m})$

J: $\quad$ Moment of inertia of the car $\left(\mathrm{kg} \cdot \mathrm{m}^{2}\right)$

$K$ : Equivalent stiffness of the guide shoe $(\mathrm{N} / \mathrm{m})$

$l_{1}$ : $\quad$ Distance between the car system mass center and the upper guide shoe $(\mathrm{m})$

$l_{2}$ : $\quad$ Distance between the car system mass center and the lower guide shoe $(\mathrm{m})$

$m$ : $\quad$ Mass of the car system $(\mathrm{kg})$

$\Delta m$ : Rated load of the car $(\mathrm{kg})$

$V: \quad$ Vertical velocity of the elevator $(\mathrm{m} / \mathrm{s})$

$Y$ : Horizontal displacement of the car (positive in the right direction) ( $\mathrm{mm}$ )

$\theta$ : Angular displacement around the centroid (positive for counterclockwise) (rad).

\section{Data Availability}

The data used to support the findings of this study are included within the article.

\section{Conflicts of Interest}

The authors declare that they have no conflicts of interest.

\section{Acknowledgments}

The authors disclosed receipt of the following financial support for the research, authorship, and/or publication of this article: National Natural Science Foundation of China 
(51875516) and Jiangsu Province Science and Technology Achievement Transforming Fund Project (BA2018083).

\section{References}

[1] R.-F. Fung, J.-H. Lin, and C.-M. Yao, "Vibration analysis and suppression control of an elevator string actuated by a pm synchronous servo motor," Journal of Sound and Vibration, vol. 206, no. 3, pp. 399-423, 1997.

[2] K. Utsunomiya, K. I. Okamoto, T. Yumura, K. Funai, and H. Kuraoka, "Active roller guide system for high-speed elevators," Elevator World, vol. 50, no. 4, pp. 86-93, 2002.

[3] X. Arrasate, S. Kaczmarczyk, G. Almandoz, J. M. Abete, and I. Isasa, "The modelling, simulation and experimental testing of the dynamic responses of an elevator system," Mechanical Systems and Signal Processing, vol. 42, no. 1-2, pp. 258-282, 2014.

[4] H. Wee, Y. Y. Kim, H. Jung, and G. N. Lee, "Nonlinear ratedependent stick-slip phenomena: modeling and parameter estimation," International Journal of Solids and Structures, vol. 38, no. 8, pp. 1415-1431, 2001.

[5] K. J. Guo, H. G. Li, and G. Meng, "Modeling and simulation of vibration for slide guide system in an elevator," Journal of Vibration and Shock, vol. 158, no. 1, p. 93, 2008.

[6] W. Fan and W. D. Zhu, "Dynamic analysis of an elevator traveling cable using a singularity-free beam formulation," Journal of Applied Mechanics, vol. 84, no. 4, Article ID 044502, 2017.

[7] S. Kobayashi, T. Yoshimura, N. Noguchi, and A. Omiya, "Estimation of dynamic characteristics of an elevator car using operational modal analysis," Transactions of the Japan Society of Mechanical Engineers Series C, vol. 74, no. 739, pp. 548-553, 2008.

[8] D.-H. Yang, K.-Y. Kim, M. K. Kwak, and S. Lee, "Dynamic modeling and experiments on the coupled vibrations of building and elevator ropes," Journal of Sound and Vibration, vol. 390, pp. 164-191, 2017.

[9] C. Wang, R. J. Zhang, and Q. Zhang, "Analysis of transverse vibration acceleration for a high-speed elevator with random parameter based on perturbation theory," The International Journal of Acoustics and Vibration, vol. 22, no. 2, pp. 218-223, 2017.

[10] D. Mei and Z. C. Chen, "Vibration analysis of high-speed traction elevator based on guide roller-rail contact model," Journal of Mechanical Engineering, vol. 45, no. 5, pp. 264-270, 2009.

[11] H. Taplak, S. Erkaya, Ş. Yildirim, and İ. Uzmay, "The use of neural network predictors for analyzing the elevator vibrations," Arabian Journal for Science and Engineering, vol. 39, no. 2, pp. 1157-1170, 2014.

[12] R. Zhang, C. Wang, and Q. Zhang, "Response analysis of the composite random vibration of a high-speed elevator considering the nonlinearity of guide shoe," Journal of the Brazilian Society of Mechanical Sciences and Engineering, vol. 40, no. 4, p. 190, 2018.

[13] R. Zhang, C. Wang, Q. Zhang, and J. Liu, "Response analysis of non-linear compound random vibration of a high-speed elevator," Journal of Mechanical Science and Technology, vol. 33, no. 1, pp. 51-63, 2019.

[14] R. M. Yani, R. Ghodsi, and E. Darabi, "A closed-form solution for nonlinear oscillation and stability analyses of the elevator cable in a drum drive elevator system experiencing free vibration," Communications in Nonlinear Science and $\mathrm{Nu}$ merical Simulation, vol. 17, no. 11, pp. 4467-4484, 2012.
[15] J. Liu, R. Zhang, Q. He, and Q. Zhang, "Study on horizontal vibration characteristics of high-speed elevator with airflow pressure disturbance and guiding system excitation," $M e$ chanics \& Industry, vol. 20, no. 3, p. 305, 2019.

[16] N. Mutoh, K. Kagomiya, T. Kurosawa, M. Konya, and T. Andoh, "Horizontal vibration suppression method suitable for super-high-speed elevators," Electrical Engineering in Japan, vol. 129, no. 1, pp. 59-73, 1999.

[17] Y. Feng, J. Zhang, and Y. Zhao, "Modeling and robust control of horizontal vibrations for high-speed elevator," Journal of Vibration and Control, vol. 15, no. 9, pp. 1375-1396, 2009.

[18] N. Noguchi, A. Arakawa, K. Miyata, T. Yoshimura, and S. Shin, "Study on active vibration control for high-speed elevators (mechanical systems)," Transactions of the Japan Society of Mechanical Engineers Series C, vol. 75, no. 754, pp. 1618-1625, 2009.

[19] N. Noguchi, A. Arakawa, K. Miyoshi, Y. Kawamura, and T. Yoshimura, "Active vibration control technology for elevator cars considering controllability," Transactions of the Japan Society of Mechanical Engineers Series C, vol. 79, no. 805, pp. 3192-3205, 2013.

[20] D. Santo, J. Balthazar, A. Tusset, V. Piccirilo, R. Brasil, and M. Silveira, "On nonlinear horizontal dynamics and vibrations control for high-speed elevators," Journal of Vibration and Control, vol. 24, no. 5, pp. 825-838, 2016.

[21] J. K. Kang and S. K. Sul, "Vertical-vibration control of elevator using estimated car acceleration feedback compensation," IEEE Transactions on Industrial Electronics, vol. 47, no. 1, pp. 91-99, 2000.

[22] B. Z. Knezevic, B. Blanusa, and D. P. Marcetic, “A synergistic method for vibration suppression of an elevator mechatronic system," Journal of Sound and Vibration, vol. 406, pp. 29-50, 2017.

[23] Q. Zhang, Z. Yang, C. Wang, Y. Yang, and R. Zhang, "Intelligent control of active shock absorber for high-speed elevator car," Proceedings of the Institution of Mechanical Engineers, Part C: Journal of Mechanical Engineering Science, vol. 233, no. 11, pp. 3804-3815, 2019.

[24] K. Nakano, R. Hayashi, Y. Suda, N. Noguchi, and A. Arakawa, "Active vibration control of an elevator car using two rotary actuators," Journal of System Design and Dynamics, vol. 5, no. 1, pp. 155-163, 2011.

[25] K. Funai, H. Kuraoka, J.-I. Higaki, and K. Utsunomiya, "104 the development of active vibration damper for elevators," The Proceedings of the Elevator, Escalator and Amusement Rides Conference, vol. 2002, pp. 13-16, 2002.

[26] M. Otsuki, Y. Ushijima, K. Yoshida, H. Kimura, and T. Nakagawa, "Application of nonstationary sliding mode control to suppression of transverse vibration of elevator rope using input device with gaps," JSME International Journal Series C, vol. 49, no. 2, pp. 385-394, 2006.

[27] A. Arakawa and K. Miyata, "A variable-structure control method for the suppression of elevator-cage vibration," in Proceedings of the IEEE 2002 28th Annual Conference of the Industrial Electronics Society (IECON 02), vol. 3, pp. 18301835, IEEE, Sevilla, Spain, November 2002.

[28] D. Y. Kim, M. R. Park, J. H. Sim, and J. P. Hong, "Advanced method of selecting number of poles and slots for low frequency vibration reduction of traction motor for elevator," IEEE/ASME Transactions on Mechatronics, vol. 22, no. 4, pp. 1554-1562, 2017.

[29] K. Utsunomiya, "Vibration damping device for an elevator," The Journal of the Acoustical Society of America, vol. 129, no. 5, p. $3419,2011$. 
[30] J. Dai, M. Han, and K. K. Ang, "Moving element analysis of partially filled freight trains subject to abrupt braking," International Journal of Mechanical Sciences, vol. 151, pp. 85-94, 2019.

[31] J. Dai, K. K. Ang, D. Jiang, V. H. Luong, and M. T. Tran, "Dynamic response of high-speed train-track system due to unsupported sleepers," International Journal of Structural Stability and Dynamics, vol. 18, no. 10, Article ID 1850122, 2018.

[32] J. Dai, K. K. Ang, M. T. Tran, V. H. Luong, and D. Jiang, "Moving element analysis of discretely supported high-speed rail systems," Proceedings of the Institution of Mechanical Engineers, Part F: Journal of Rail and Rapid Transit, vol. 232, no. 3, pp. 783-797, 2018.

[33] S. Mikko, H. Tapio, and O. Matti, "Optimization of lift car vibration behavior by modal analysis," Elevator World, vol. 33, no. 6, pp. 39-43, 1985.

[34] K. Okada and N. Nishimura, "Noise and vibration reduction techniques for $750 \mathrm{~m} / \mathrm{min}$ elevators," Elevator World, vol. 48, no. 11 , pp. 76-78, 2000.

[35] Y. Yamazaki, M. Tomisawa, K. Okada, and Y. Sugiyama, "Vibration control of super-high-speed elevators: car vibration control method based on computer simulation and experiment using a full-size car model," JSME International Journal Series C, Dynamics, Control, Robotics, Design and Manufacturing, vol. 40, no. 1, pp. 74-81, 1997.

[36] M. Tadashi and K. Hideya, "The world's fastest elevator," Elevator World, vol. 51, no. 9, pp. 97-101, 2003.

[37] K. Funai, "The development of active vibration damper for super-high-speed elevators," Lift Report, vol. 5, no. 1, pp. 22-37, 2004.

[38] J. M. Krodkiewski, Mechanical Vibration, The University of Melbourne, Melbourne, Australia, 2008.

[39] N. Shigeyuki, M. Keiji, and T. Masaharu, "Parametric vibration of elevator," Transactions of the Japan Society of Mechanical Engineers, Series C, vol. 62, no. 600, pp. 30373045, 1996.

[40] W. J. Fu, C. M. Zhu, and C. Y. Zhang, "Modeling and simulation for dynamics of single wrapped elevator," Journal of System Simulation, vol. 17, no. 3, pp. 635-638, 2005.

[41] W. D. Iwan and P.-T. Spanos, "Response envelope statistics for nonlinear oscillators with random excitation," Journal of Applied Mechanics, vol. 45, no. 1, pp. 170-174, 1978.

[42] ISO 18738-1:2012, Lifts (Elevators)-Measurement of Ride Quality, International Organization for Standardization, Geneva, Switzerland, 2012.

[43] R. Srinivasan, Importance Sampling, Springer-Verlag, Berlin, Germany, 2002.

[44] K. M. Portier, “Adaptive sampling," Technometrics, vol. 39, no. 2, p. 236, 1997.

[45] G. O. Roberts and W. R. Gilks, Convergence of Adaptive Direction Sampling, Academic Press Inc., Cambridge, MA, USA, 2008.

[46] W. X. Zhong and F. W. Williams, "A precise time step integration method," Proceedings of the Institution of $\mathrm{Me}$ chanical Engineers, Part C: Journal of Mechanical Engineering Science, vol. 208, no. 63, pp. 427-430, 1994.

[47] W. X. Zhong, Y. K. Cheung, and Y. Li, "The precise finite strip method," Computers \& Structures, vol. 69, no. 6, pp. 773-783, 1998.

[48] A. Alipanah and S. Esmaeili, "Numerical solution of the twodimensional Fredholm integral equations using Gaussian radial basis function," Journal of Computational and Applied Mathematics, vol. 235, no. 18, pp. 5342-5347, 2011.
[49] K. Deb, A. Pratap, S. Agarwal, and T. Meyarivan, "A fast and elitist multiobjective genetic algorithm: NSGA-II," IEEE Transactions on Evolutionary Computation, vol. 6, no. 2, pp. 182-197, 2002.

[50] P. Limbourg and D. E. S. Aponte, "An optimization algorithm for imprecise multi-objective problem functions," in Proceedings of the 2005 IEEE Congress on Evolutionary Computation, no. 1, pp. 459-466, Edinburgh, Scotland, September 2005.

[51] https://www.pmtvib.com/eva-625. 